\title{
MINLP model and two-stage algorithm for the simultaneous synthesis of heat exchanger networks, utility systems and heat recovery cycles
}

\author{
Emanuele Martelli ${ }^{\mathrm{a}, *}$, Cristina Elsido $^{\mathrm{a}}$, Alberto Mian ${ }^{\mathrm{b}}$, Francois Marechal ${ }^{\mathrm{b}}$ \\ a Politecnico di Milano, Department of Energy, Via Lambruschini 4, 20156 Milano, Italy \\ ${ }^{\mathrm{b}}$ Ecole Politechnique Fédérale de Lausanne, Station 9, 1015 Lausanne, Switzerland
}

\section{A R T I C L E I N F O}

\section{Article history:}

Received 30 September 2016

Received in revised form 21 January 2017

Accepted 24 January 2017

Available online 6 February 2017

\section{Keywords:}

HEN synthesis

Heat integration

Steam cycles

Utility synthesis

MINLP

MILP

\begin{abstract}
A B S T R A C T
This work proposes a novel approach for the simultaneous synthesis of Heat Exchanger Networks (HEN) and Utility Systems of chemical processes and energy systems. Given a set of hot and cold process streams and a set of available utility systems, the method determines the optimal selection, arrangement and design of utility systems and the heat exchanger network aiming to rigorously consider the trade-off between efficiency and capital costs. The mathematical formulation uses the SYNHEAT superstructure for the HEN, and ad hoc superstructures and nonlinear models to represent the utility systems. The challenging nonconvex MINLP is solved with a two-stage algorithm. A sequential synthesis algorithm is specifically developed to generate a good starting solution. The algorithm is tested on a literature test problem and two industrial problems, the optimization of the Heat Recovery Steam Cycle of a Natural Gas Combined Cycle and the heat recovery system of an Integrated Gasification Combined Cycle.
\end{abstract}

(C) 2017 Elsevier Ltd. All rights reserved.

\section{Introduction}

The optimal design of energy systems and chemical processes involves the synthesis of the Heat Exchanger Network(HEN) and the utility systems necessary to provide thermal, refrigeration and electric power to the process units. The so-called heat integration problem aims at determining structure and design variables (inlet/outlet temperatures, mass flow rates and heat exchanger areas) of the process HEN, and the selection, structure and design variables of the utility systems. Both tasks involve the optimization of integer (binary) variables. When optimizing the HEN, integer variables are needed to select the heat exchangers among all the possible matches between hot and cold streams (Yee and Grossmann, 1990). When designing the utility systems, integer variables are needed to select the type of utility system (Marechal and Kalitventzeff, 1998) and to define its arrangement (Papoulias and Grossmann, 1983a). As a result, the overall optimization problem (HEN + utility) is a Mixed Integer Non-Linear Problem (MINLP) and its combinatorial nature makes it very difficult to solve. Indeed, the optimization problem of just the HEN (without utility systems) is proven to be "NP-Hard" in the strong sense (Furman and Sahinidis, 2002).

To the best of our knowledge, all the available synthesis techniques tackle the problems of the optimization of the design of the HEN and of the utility systems (e.g., steam cycle) separately. The separate approach limits the set of integration options between the HEN and the set of utility streams. For instance, the well-known sequential approach proposed in the works of Papoulias and Grossmann (1983a, 1983b), and Floudas et al. (1986) are limited by the fact that utility systems are designed after optimizing the HEN, with the objective of providing to the HEN the required hot/cold utility loads. The following limitations are implied:

1. As far as steam cycles/networks are concerned, in Papoulias and Grossmann (1983a) it is assumed that the utility streams available for supplying/removing heat from the process can be only evaporating/condensing steam. For instance, hot process streams cannot economize feedwater or superheat steam. This limitation to the possible integration options between utility and HEN may be suitable only for chemical processes (where saturated steam is typically used) but not for power plants, like Integrated Gasification Combined Cycles (Martelli et al., 2011b);

\footnotetext{
* Corresponding author.

E-mail address: emanuele.martelli@polimi.it (E. Martelli).
} 


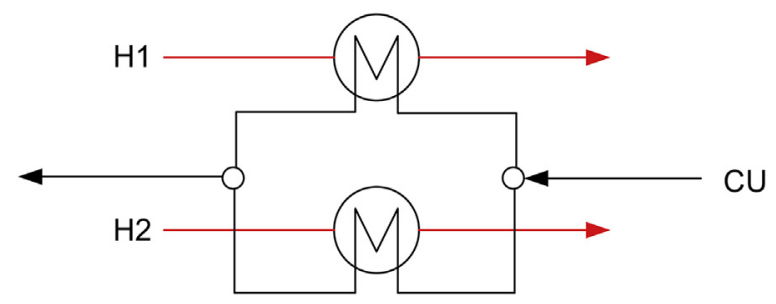

Fig. 1. Parallel branches of utility streams assumed in Floudas et al. (1986).

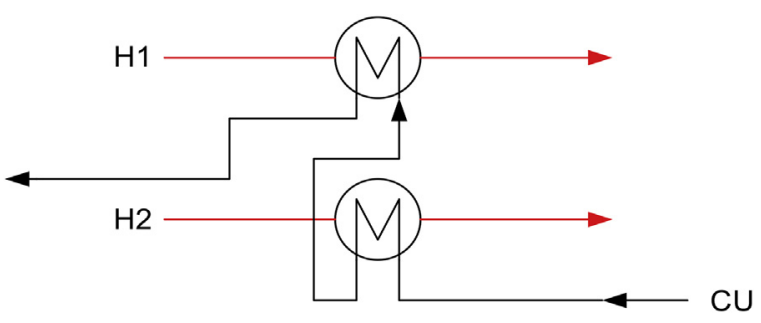

Fig. 2. Utility streams with matches in series.

2. In the NLP superstructure of Floudas et al. (1986), the matches of each utility stream can only be in parallel. Indeed, it is considered one utility sub-stream for each match which involves the given utility: i.e., if a cold utility stream (CU) has two matches, one with stream $\mathrm{H} 1$ (H1-CU) and one with $\mathrm{H} 2$ (H2-CU), when building the HEN they are considered as two different streams, stream CU1, matched with H1, and stream CU2, matched with H2 (see Fig. 1). This implies that, for the CU stream the series arrangement H1-CU - H2-CU (shown in Fig. 2) is excluded from the HEN;

3. Because of limitation (2) which imposes the parallel arrangement, the outlet temperature of cold utility stream must be lower than the inlet temperature of the matching hot stream. For the same reasons, the outlet temperature of the hot utility stream must be higher than the inlet temperature of the cold streams matched. This constraint does not allow to use cold utility streams with high outlet temperatures (e.g., feedwater of a steam cycle whose target temperature is $200-300^{\circ} \mathrm{C}$ ) or hot utility streams with low outlet temperatures (e.g., the flue gases of a gas turbine which can be cooled down to $100-60^{\circ} \mathrm{C}$ ) which are the streams of the most efficient utility systems.

Also simultaneous HEN synthesis techniques, such as (Yee and Grossmann, 1990) and its improved versions (Björk and Westerlund, 2002; Bergamini et al., 2007), have limitations which make them not suitable for designing HENs optimally integrated with utility systems. In detail, the MINLP SYNHEAT superstructure of (Yee and Grossmann, 1990) has the following limitations:

1. Utility superstructures/models are not included for selection and optimization;

2. The optimization of the utility stream mass flow rates is not tackled because it would make the MINLP more difficult to solve (constraints would become nonlinear and nonconvex due to the bilinear terms corresponding to the products between utility mass flow rates and stage temperatures);

3. Utility streams are not included in the HEN superstructure but placed at the hot and cold ends of the superstructure;

4. The matches of each utility stream can only be in parallel since it is considered one utility sub-stream for each possible match with the process stream (i.e., the configuration of Fig. 2 cannot be reproduced).

In utility synthesis techniques, like that proposed by Bruno et al. (1998), the optimization of the HEN is not dealt with. The utility system is optimized to provide thermal, electric and refrigeration power to the process (for fixed process requirements, i.e., assuming that the process HEN has been already determined in a previous step). Among the simultaneous synthesis techniques for HENs with multiple utilities, like those proposed by Isafiade et al. (2015), Na et al. (2014), Ponce-Orega et al. (2010), to the best of our knowledge, only the superstructure proposed by Isafiade and Fraser (2008) allows to place the matches of utility streams in series because it regards utility streams as process streams. All the other above-cited techniques do not envisage the possibility for utility streams to have matches in series (as in Fig. 2) so as to avoid non-convex terms (i.e., bilinear terms due to the products between utility mass flow rates and stage temperatures). On the other hand, the interval-based superstructure of Isafiade and Fraser (2008) is not as flexible as that of Yee and Grossmann (1990) and Isafiade et al. (2015), Na et al. (2014), Ponce-Ortega et al. (2008) because the temperature stages are defined on the basis of the supply and target temperatures of the hot streams. Consequently, (1) the matches of each cold stream with the hot streams are necessarily sequenced according to the order of temperatures of the hot streams, (2) some streams with narrow temperature range can have only one stage with the impossibility of having two or more matches in series. This limitation may significantly penalize the area cost of the solution if hot streams have considerably different heat transfer coefficients (in such a case the optimal order of the matches may not coincide with the order of stream temperatures) or if the series arrangement is economically advantageous (see the test case in Section 6). Another important limitation of all above-cited simultaneous synthesis techniques for HENs with multiple utilities is that the design and synthesis of the utility systems are not tackled. 
To the best of our knowledge, only the sequential approaches proposed by Papoulias and Grossmann (1983c), Marechal and Kalitventzeff (1989, 1998, 1999) and Duran and Grossmann (1986) are able to optimize the synthesis of utility systems and HENs while considering all the possible integration options between process and utility systems. The three approaches use in the first step a targeting method to determine the optimal utility selection and mass flow rates without dealing with the combinatorial problem associated to the design of the HEN. In a second step, for fixed utility streams (and mass flow rates), the HEN is optimized. In the first step of the approach proposed by Papoulias and Grossmann (1983c), the LP transhipment model of the heat recovery network is combined with the superstructure of the utility system and the superstructure of the chemical plant. Since both models of the utility system and chemical plant are restricted to be linear, the integrated optimization problem is a large-scale MILP with the minimum utility cost as objective function. While mass flow rates are continuous decision variables, only a discrete set of possible stream pressures and temperatures can be considered (for the chemical plant and the utility systems) because of the necessity of avoiding nonlinearities in the models. In the second step, once all the stream mass flow rates, temperatures and pressures have been determined, the HEN with minimum number of units is determined using the MILP transhipment model of Papoulias and Grossmann (1983b). With the aim of optimizing the stream temperatures and pressures (of both the chemical plant and the utility systems) without the necessity of discretization, Duran and Grossmann (1986) devise a methodology using a pinch location method for the targeting step. The key advantage compared to the LP transhipment model is the possibility of determining the utility costs (energy targeting) without fixing a priori the temperature intervals. Thus, the optimization of the overall plant (chemical process, utility system and heat integration) can be formulated as a NonLinear Program (NLP) with the stream mass flow rates and temperatures as real variables. On the other hand, compared to Papoulias and Grossmann (1983c), forbidden/forced matches cannot be handled within the NLP. In Yang and Grossmann (2013), the Duran and Grossmann (1986) procedure is combined with a water targeting model and integrated in a simultaneous flowsheet optimization process with the aim of predicting the best operating conditions (e.g., stream temperatures) and stream mass flow rates.

In Marechal and Kalitventzeff $(1989,1998,1999)$, first, the utility selection and the flow rates of the utility streams are determined for fixed stream conditions (temperatures and pressure levels) by solving an extended LP transhipment problem which uses binary activation variables for the utility selection and allows to optimize the utility mass flow rates. Then the targeting problem is formulated as a small scale MILP. In the second step, the HEN is optimized for fixed utility mass flow rates with the classic sequential approach (i.e., minimum number of units and minimum area network). More recently, Gassner and Maréchal (2007) extend the methodology to the optimization of the stream pressures and temperatures by devising a bi-level approach: at the upper level an evolutionary algorithm optimizes the stream pressures and temperatures of both process and utility systems, and at the lower level the utility selection and stream mass flow rates are optimized with the extended LP transhipment problem of Marechal and Kalitventzeff $(1989,1998,1999)$.

The main shortcomings of these three sequential methodologies are:

1) They do not allow to rigorously optimize the trade-off between capital cost of utility systems, capital cost of the HEN, operating costs and energy efficiency due to their sequential decomposition.

2) In Marechal and Kalitventzeff (1989, 1998, 1999) and Papoulias and Grossmann (1983c), utility systems are selected and sized (i.e., determine their mass flow rates) in the first step by solving a MILP problem which requires a linear objective function (total energy consumption or linearized total utility cost), excluding the possibility of defining nonlinear cost functions.

3) It is not possible to impose the "no stream splitting" constraint (i.e., a subset of streams can have matches only in series) and other similar constraints on the topology of the HEN which alter the prediction made with the targeting procedure.

The last one is an important limitation when dealing with the detailed design of power plants and chemical processes. Indeed, in large gas-gas or gas-steam heat exchangers (e.g., Heat Recovery Steam Generators (HRSG) and syngas coolers), the steam tube banks are typically placed in series and not in parallel for technical and economic reasons. For example, in a HRSG, the tube banks of the superheater and reheater are typically placed in series with respect to the stream of flue gas (see Fig. 3c), even though the parallel arrangement could allow to save some heat transfer area. The series layout is adopted for two main reasons: (1) given the large volumetric flow rate of gas, it is not worth splitting the gas stream in two branches because two shells/cases would be required with a significant increase of investment cost, (2) within the available cross sectional area of the shell/case, tube banks of different streams cannot be placed in parallel (e.g., SH and RH in parallel, as in Fig. 3a or b) because of the large number of parallel tubes necessary for each stream. Indeed, with the aim of limiting the gas/steam-side pressure drops (which would cause excessive loss of efficiency to the power cycle), relatively low velocities must be adopted for the fluids across the tube banks. As a result, the volumetric flow of each stream (e.g., SH and RH) must be split over a large number of parallel tubes. These parallel tubes depart from a header and occupy the whole cross sectional area of the heat exchanger (Fig. 3c). To adopt the parallel arrangement of the tube banks of Fig. $3 a$ would lead to expensive designs with short tubes and doubled number of $U$ bends, with increased manufacturing costs and failure risks. Instead, to adopt the parallel arrangement of Fig. 3b would lead to either too high pressure drops (if the steam velocity in the tube banks is doubled so as to halve the number of necessary parallel tubes) or to too expensive header designs and tube arrangements. As an additional reason, the series arrangement of Fig. 3c allows to place steam desuperheaters (i.e., injection of small amounts of liquid water in the superheated steam) between the different steam tube banks and, in this way, to avoid overheating of the superheater and reheater tubes.

Recently Mian et al. (2016) have proposed an improved version of the approach devised by Marechal and Kalitventzeff (1989, 1998, 1999) with the aim of overcoming the first two limitations. Indeed the authors combine the sequential approach of Marechal and Kalitventzeff $(1998,1999)$ with the derivative-free algorithm PGS-COM Martelli and Amaldi (2014) which improves the returned solutions by optimizing the selection, size, and design (temperature levels) of the utilities, heat recovery approach temperatures of each stream, and the penalty levels associated to matches between streams. However, it is worth noting that, in order to address the third limitation, a simultaneous synthesis approach (i.e., without sequential decomposition) is necessary.

This work proposes an approach and algorithm for the simultaneous synthesis of HENs and utility systems, which allows to overcome all the above-listed limitations. In particular, the approach allows to (1) select among several available utility systems, (2) include complex superstructures of utility systems (e.g., multiple-pressure-level steam cycles), (3) generate any possible match between process streams and utility streams (i.e., matches between process and utility streams are not necessarily placed at the hot/cold ends of 

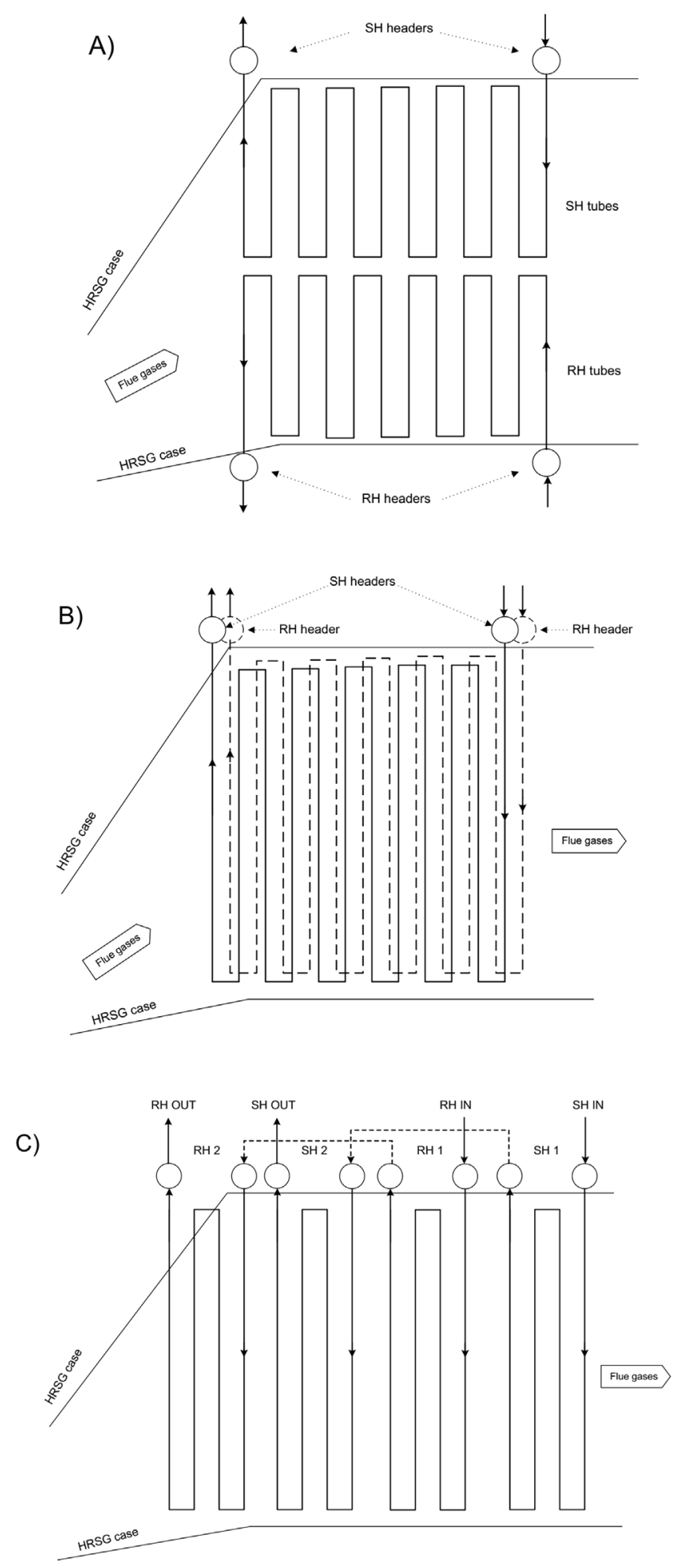

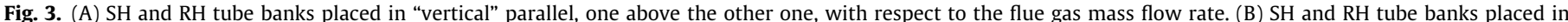

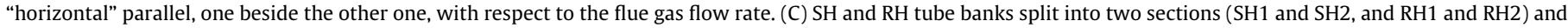
placed in series with respect to the flue gas flow rate.

the HEN superstructure) so as to exploit any possible synergy between process and utility streams, (4) configure and optimally design the utility systems (e.g., selection of steam pressure levels) and HEN simultaneously, aiming to rigorously determine the optimal tradeoff between efficiency, number of heat exchangers, and area taking into account of the stream heat transfer coefficients, (5) include design constraints on the HEN like "forbidden matches", "restricted matches" and "no stream splitting". Although it could be included in the model and optimization algorithm, the optimization of the stream temperatures and pressures will be dealt with in a forthcoming publication. 


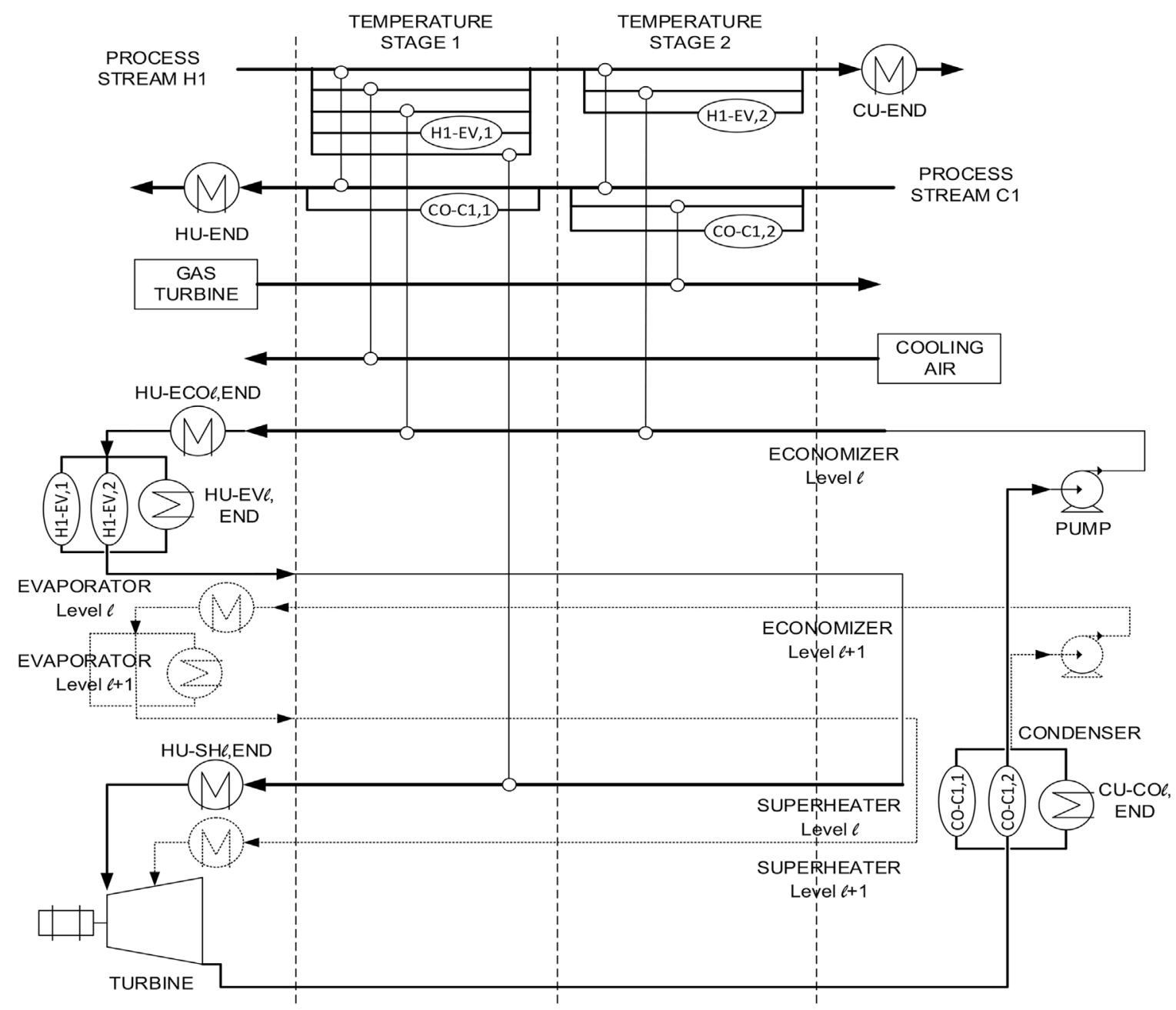

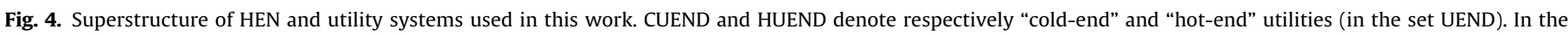

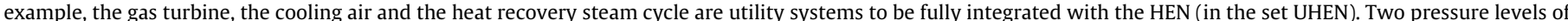

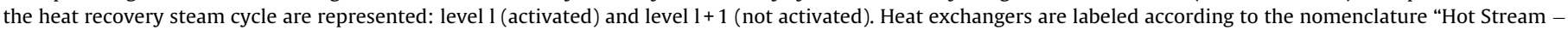
Cold Stream, stage number".

\section{Problem statement and superstructure}

The problem can be stated as below:

"Given a set of hot and cold process streams with given mass flow rates, inlet and outlet temperatures, and a set of available utility systems with given structure or superstructure of possible configurations (e.g., multiple steam pressure levels), the method simultaneously determines the optimal selection of utility systems, their design (selection of pressure levels, arrangement of the heat exchangers of the utility systems, mass flow rates of each utility stream, etc.), and the HEN between process-process as well as process-utility and utility-utility streams, minimizing the Total Annual Cost (TAC) of both utility systems and HEN".

In order to tackle this problem, it is necessary to select a suitable HEN superstructure and combine it with models and superstructures of utility systems. Among the available HEN superstructures, the SYNHEAT temperature-stage HEN superstructure of Yee and Grossmann (1990) has been selected. Although it is limited by the isothermal mixing assumption compared to other superstructures (e.g., (Ciric and Floudas, 1991)), it often leads to better solutions on industrial scale problems, as shown by Escobar and Trierweiler (2013), because of the linearity of the constraints which makes the problem easier to solve.

As far as utility systems are concerned, they may feature a single hot/cold stream (e.g., cooling water, cooling air, etc.) or multiple streams (e.g., steam cycles, refrigeration cycles, etc.). Utility systems are divided into two subsets:

- UEND = set of hot/cold utility systems placed at the hot/cold ends of the HEN (as in the original SYNHEAT superstructure);

- UHEN = set of hot/cold utility systems to be included into the HEN superstructure as process streams with variable mass flow rate.

The overall superstructure including HEN and utility systems is represented in Fig. 4.

The streams of utilities in UHEN can be fully integrated in the HEN, indeed they are dealt with as process streams (e.g., the gas turbine flue gases, the cooling air and the streams of the steam cycle in Fig. 4). Streams of utilities in UEND instead are not included in the HEN superstructure and they are placed at the hot/cold ends of the HEN (as done in Yee and Grossmann (1990). As a result, utility streams in UEND have limited matching options with other streams. However, they require a much lower number of binary and real variables compared to utility streams in UHEN (see Section 3). A utility is included in UEND only if its streams have very hot/cold inlet and outlet 
temperatures compared to those of the cold/hot streams. In such a case, the optimal matching is likely to be at the hot/cold ends of the HEN superstructure. If this condition is not verified, it is advisable to include the utility in UHEN so as not to exclude better matching options.

While any utility can be included in set of UHEN, only those which satisfy the following condition on the outlet temperatures of the streams can be defined in UEND.

- For cold utility streams: the outlet temperature of the cold utility stream must be lower than the inlet temperatures of the hot process streams. For example, if refrigeration of process streams below ambient temperature is not required, cooling water can be considered as "cold-end" utility CUEND (i.e., cold utility in UEND).

- For hot utility streams: the outlet temperature of the hot utility stream must be higher than the inlet temperatures of the cold process streams. Typically, furnaces can be considered as "hot-end" utility HUEND (i.e., hot utility in UEND).

Of course, UEND is the union of HUEND and CUEND (UEND = HUEND $\cup$ CUEND). It is worth noting that the set UEND may be empty if no utility can be reasonably classified as "hot/cold end" utility. Moreover, a stream may not have a "hot/cold-end" utility because its target temperature is variable (e.g., the Gas Turbine flue gases in Fig. 4).

In the superstructure of Fig. 4, the set UHEN includes the gas turbine (hot utility with a single stream), the cooling air (cold utility with a single stream) and a heat recovery steam cycle featuring multiple pressure levels (levels $l$ and $l+1$ are represented). For the heat recovery steam cycle (HRSC), a simplified version of the detailed model proposed by Martelli et al. (2011a) has been adopted. The HRSC model features the key hot (i.e., condenser) and cold streams (i.e., economizers, evaporators and superheaters/reheaters), the turbine and the pump required for the correct calculation of the energy and mass balance equations. Thus, the steam cycle model features at least three cold streams (economizer, evaporator, and superheater) and one cold stream (condenser) for each pressure level $l$. A more detailed steam cycle superstructures including feedwater preheaters (regenerators), deareator as well as steam extractions at multiple levels, like those used in Martelli et al. (2013), Martelli et al. (2012) could be easily included.

In order to deal with the utility and process streams with infinite specific heat capacity (i.e., isothermal streams like evaporators and condensers), the approach of Ponce-Ortega et al. (2008) has been adopted. The typical approach of considering very high $c_{\mathrm{p}}$ for isothermal streams (introducing a small fictitious temperature increase/decrease) generates numerical issues to the optimization algorithms due to the poor scaling of the problem variables. Besides, for isothermal streams like evaporators and condensers, there is no saving of heat transfer area to connect heat exchangers in series. Also in the real practice evaporators/condensers are never connected in series: parallel branches of saturated steam/liquid are extracted from a header and each branch is sent to its own condenser/evaporator and returned to the liquid/steam header. For these reasons, in the proposed superstructure evaporating and condensing isothermal streams can only have parallel matches with the other streams (as shown in Fig. 4). From a mathematical point of view, compared to streams with sensible heat (finite $c_{\mathrm{p}}$ ), for the isothermal streams it is possible to avoid not only the variables corresponding to the temperatures of the streams at the inlet/outlet of the temperature stages, but also, for utility streams, the challenging bilinear (nonconvex) products between mass flow rates and stage temperatures (see Section 3). These two advantages lead to a significant saving of computational time compared to using the original SYNHEAT superstructure without any adaption.

Process and utility streams may also have a variable outlet temperature, as the flue gases of the gas turbine and the cooling air shown in the example of Fig. 4. This allows to properly model heat recovery applications from flue gases (whose outlet temperature is not fixed and typically it must only be higher than a lower bound) and determine the best design (i.e., fluid mass flow rate, outlet temperature and heat transfer area) of heat rejection systems.

Moreover, in the proposed methodology, heat exchangers may have different costs (fixed cost of activation $C a_{i j}$ and specific area cost $C_{i j}$ in $\$ / \mathrm{m}^{2}$ ), depending on the type of design (e.g., shell and tube, finned tube, plate type, concentric tube), pressure, and material (carbon steel, stainless steel, high grade steel, etc.), as well as different overall heat transfer coefficient $U_{i j}$ depending on the heat transfer coefficients of the involved streams $i$ and $j$.

\section{MINLP model formulation}

The MINLP problem associated to the above-described superstructure is based on the following assumptions which do not appreciably penalize the general applicability of the model:

- Streams have constant specific heat capacities;

- Streams have constant heat transfer coefficients;

- All heat exchangers have a counter-flow arrangement;

- Stream branches exit each stage at the same temperature and are mixed before entering the subsequent stage (isothermal mixing assumption).

It is worth noting that the last two simplifications are well matched to the design problem of utility systems (such as steam cycles) and energy systems (e.g., Integrated Gasification Combined Cycles) which are typically designed targeting the maximum efficiency. Indeed, from a thermodynamic point of view, counter-flow heat exchangers allow a higher heat recovery and lower exergy penalty than parallelflow heat exchangers, and the isothermal mixing assumption avoids the exergy penalty associated to the irreversible heat transfer process occurring in the mixer.

The following sections detail the data, variables, constraints and objective function of the MINLP problem.

Indices

$$
\begin{aligned}
& i=\text { index to denote the hot process or utility streams } \\
& j=\text { index to denote the cold process or utility streams } \\
& k=\text { index to denote the temperature stages }[1: \text { NOK] and temperature locations }[1: N O K+1]
\end{aligned}
$$


Sets

$u=$ index to denote utility systems

$H O T=\{i \mid i$ is a hot process or utility stream $\}$

$C O L D=\{j \mid j$ is a cold process or utility stream $\}$

$H P$ in $H O T=\{i \mid i$ is a hot process stream $\}$

$C P$ in $C O L D=\{j \mid j$ isacold process stream $\}$

$\mathrm{UHEN}=\{u \mid u$ is a utility with streams included in the HEN superstructure $\}$

$H_{-} U H E N_{u}$ in $H O T=\{i \mid i$ is a hot stream of the utility $u$ in UHEN $\}$

$C_{-} U_{H E N}$ in $C O L D=\{j l j$ is acold stream of the utility $u$ inUHEN $\}$

CO in HOT $=\{i \mid i$ is a hot process or utility isothermal (condensing) stream $\}$

$E V$ in $C O L D=\{j j j$ is a cold process or utility isothermal (evaporating) stream $\}$

$S T=\{k \mid k$ is a stagein the superstructure, $k \in[1: N O K]\}$

$S S=\{i \mid i$ is a stream that cannot be split into branches $\}$

$F M=\{(i, j) \mid$ the match between hot stream $i$ and cold stream $j$ is forbidden $\}$

$R M=\{(i, j) \mid$ the match betweenhot streami and cold stream $j$ is restricted to a maximumamount of heat that can be exchanged $\}$

$R Q=\{(i, j) \mid$ thematch between hotstreami and cold stream $j$ is required, i.e., aminimumamount of heat must be exchanged $\}$

$C_{u}=\{l \mid l$ is an equipment unit of theutility system $u\}$

Parameters

$I=$ total number of hot streams

$J=$ total number ofcold streams

$N O K=$ total number of stages

$\operatorname{TIN}_{i}=$ inlet temperature of non - is othermal stream $i$

$\operatorname{TOUT}_{i}=$ outlet temperatureof non - isothermal streami

$\mathrm{Tco}_{i}=$ condensating temperature of isothermal hot stream $i$

$T e v_{j}=$ evaporating temperature of isothermal cold stream $j$

$F_{i}=$ flow rate of process streami

$C p_{i}=$ specific heat capacity of non - isothermal stream $i$

$\lambda_{i}=$ specific latent (condensation or evaporation) heat of isothermalstream $i$

$U_{i j}=$ overall heat tansfer coefficient between hot stream $i$ and coldstream $j$

$\Omega_{i j}=$ upper bound for heat exchange between hot stream $\mathrm{i}$ and cold stream $\mathrm{j}$

$\Delta \operatorname{Tmax}_{i j}=$ upper bound for temperature between difference hot stream $\mathrm{i}$ and cold stream $\mathrm{j}$

$C_{C U, i}=$ unit cost for cold UEND utility matched with hot stream $i$

$C_{H U, j}=$ unit cost for hot UEND utility matched with cold stream $j$

$C a_{i j}=$ fixed cost of activation for a match between hot stream $i$ and cold stream $j$

$C_{i j}=a$ rea cost coefficient for a match between hot stream $i$ and cold stream $j$

$B=$ exponent for area cost

$F C_{i j}=$ fixed charge for heat exchanger related to match $(i, j)$

$\dot{Q}_{\max , i j}=$ maximum heat that can be exchanged by streams $(i, j) \in R M$

$\dot{Q}_{\min , i j}=$ minimum heat that can be exchanged by streams $(i, j) \in R Q$

$\Gamma_{\max , i}=$ maximum mass flow rate of stream $i\left(i i n H_{-} U H E N_{u}, C_{-} U H E N_{u}\right)$ 
Decision variables

$q_{i j k}=$ heat exchanged between hot streamiand cold streamjin stage $k$

$q c u_{i}=$ heat exchanged between hot stream $i$ and cold UEND utility

$q h u_{j}=$ heat exchanged between hot UEND utility and cold stream $j$

$q c u_{t o t}=$ total heat duty of the cold - endutility

$q h u_{t o t}=$ total heat duty of the hot - endutility

$q_{i n}=$ heat absorbed by the component $l$ of the utility system $u$

pout $_{l}=$ mechanical power extracted by the component $l$ of the utility system $u$

$t_{i, k}=$ temperature of non isothermal hot stream $i$ at hot end of stage $k$

$t_{j, k}=$ temperature of non isothermal cold stream $j$ at hot end of stage $k$

$d t_{i j k}=$ temperature approach for match $(i, j)$ at temperature location $k$

$d t c u_{i}=$ temperature approach for the match of hot stream $i$ and cold UEND utility

$d t h u_{j}=$ temperature approach for the match of cold stream $j$ and hot UEND utility

$z_{i j k}=$ binary variable to denote the activation of the match $(i, j)$ in stage $k$

$z c u_{i}=$ binary variable to denote the activation of the heat exchanger between the cold UEND utility and hot stream $\mathrm{i}$

$z h u_{j}=$ binary variable to denote the activation ofthe heat exchanger between the hotutility UEND and cold stream $\mathrm{j}$

$y_{u}=$ binary variable to denote the activation of the UHEN utility $u$

$y_{c u}=$ binary variable to denote the activation of the cold UEND utility

$y_{h u}=$ binary variable to denote the activation of the hot UEND utility

$\Gamma_{i}=$ flow rate of utility stream $i\left(i i n H_{-} U H E N_{u}, C_{-} U H E N_{u}\right)$

Constraints

(1) Heat transfer direction:

$q_{i j k} \geq 0, \forall i \in H O T, j \in C O L D, k \in S T$

(2) Energy balance for each process and utility stream

An overall heat balance of each stream is needed to ensure that it reaches the outlet target temperatures (or enthalpies):

$$
\begin{aligned}
& \left(\operatorname{TIN}_{i}-\mathrm{TOUT}_{i}\right) * F_{i} * C p_{i}=\sum_{k \in S T j \in C O L D} \sum_{i j k}+q c u_{i}, \forall i \in H P, i \notin C O \\
& \left(\mathrm{TOUT}_{j}-\mathrm{TIN}_{j}\right) * F_{j} * C p_{j}=\sum_{k \in S T i \in H O T} \sum_{i j k}+q h u_{j}, \forall j \in C P, j \notin E V \\
& F_{i} * \lambda_{i}=\sum_{k \in S T j \in C O L D} \sum_{i j k}+q c u_{i}, \forall i \in H P \cap C O \\
& F_{j} * \lambda_{j}=\sum_{k \in S T i \in H O T} \sum_{i j k}+q h u_{j}, \forall j \in C P \cap E V \\
& \left(\operatorname{TIN}_{i}-\text { TOUT }_{i}\right) * \Gamma_{i} * C p_{i}=\sum_{k \in S T} \sum_{j \in C O L D} q_{i j k}+q c u_{i}, \forall i \in \underset{u \in U H E N}{\cup} H_{U H E N u}, i \notin C O \\
& \left(\text { TOUT }_{j}-\text { TIN }_{j}\right) * \Gamma_{j} * C p_{j}=\sum_{k \in S T i \in H O T} \sum_{i j k} q_{i j k}+q h u_{j}, \forall j \in \underset{u \in U H E N}{\cup} C_{U H E N u}, j \notin E V \\
& \Gamma_{i} * \lambda_{i}=\sum_{k \in S T j \in C O L D} \sum_{i j k}+q c u_{i}, \forall i \in \underset{u \in U H E N}{\cup} H_{-} U_{H H E N} \cap C O
\end{aligned}
$$

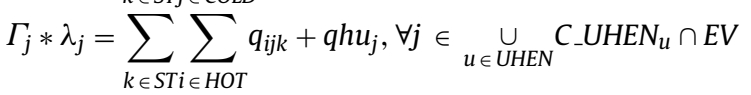

(3) Energy balance of non-isothermal process and utility streams in each stage 
An energy balance of non-isothermal process and utility streams included in the HEN is necessary in order to determine the stage exit temperatures. For utility streams such constraints are nonconvex because of the products between mass flow rates $\Gamma_{i}$ and stage temperatures $\left.t_{i, k}\right)$ :

$$
\begin{aligned}
& \left(t_{i, k}-t_{i, k+1}\right) * F_{i} * C p_{i}=\sum_{j \in C O L D} q_{i j k}, \forall k \in S T \forall i \in H P, i \notin C O \\
& \left(t_{j, k}-t_{j, k+1}\right) * F_{j} * C p_{j}=\sum_{i \in H O T} q_{i j k}, \forall k \in S T \forall j \in C P, j \notin E V \\
& \left(t_{i, k}-t_{i, k+1}\right) * \Gamma_{i} * C p_{i}=\sum_{j \in C O L D} q_{i j k}, \forall i \in \underset{u \in U H E N}{\cup} H_{-} U_{H E N}, i \notin C O \\
& \left(t_{j, k}-t_{j, k+1}\right) * \Gamma_{j} * C p_{j}=\sum_{i \in H O T} q_{i j k}, \forall j \in \underset{u \in U H E N}{\cup} C_{-} U_{H E N} . j \notin E V
\end{aligned}
$$

(4) Assignment of superstructure inlet temperatures

Inlet temperatures of process and utility streams are input parameters:

$$
\begin{aligned}
& \operatorname{TIN}_{i}=t_{i, 1}, \forall i \in H O T, i \notin C O \\
& \operatorname{TIN}_{j}=t_{j, N O K+1}, \forall j \in C O L D, j \notin E V
\end{aligned}
$$

(5) Monotonic temperature variation

These constraints are to guarantee the monotonic decrease/increase in temperatures along the stages and to bound the outlet temperature of streams (for isothermal streams these constraints are not necessary because the temperature is the same in all stages):

$$
\begin{aligned}
& t_{i, k} \geq t_{i, k+1}, \forall k \in S T \forall i \in H O T, i \notin C O \\
& t_{j, k} \geq t_{j, k+1}, \forall k \in S T \forall j \in C O L D, j \notin E V \\
& \text { TOUT }_{i} \leq t_{i, N O K+1}, \forall i \in H O T, i \notin C O \\
& \text { TOUT }_{j} \geq t_{j, 1}, \forall j \in C O L D, j \notin E V
\end{aligned}
$$

(6) Load of utilities in UEND

The heat load requirement of the two utility systems placed at the hot and cold ends of the superstructure is given by the following constraints. It should be noticed that the utility heat duties for isothermal streams have already been considered in the overall heat balance constraints (2):

$$
\begin{aligned}
& \left(t_{i, N O K+1}-\mathrm{TOUT}_{i}\right) * F_{i}=q c u_{i}, \forall i \in H P, i \notin C O \\
& \left(\text { TOUT }_{j}-t_{j, 1}\right) * F_{j}=q h u_{j}, \forall j \in C P, j \notin E V \\
& \left(t_{i, N O K+1}-T_{T O U T}\right) * \Gamma_{i}=q c u_{i}, \forall i \in \underset{u \in U H E N}{\cup} H_{-} U_{H E N}, i \notin C O \\
& \left(T_{O U U T}-t_{j, 1}\right) * \Gamma_{j}=q h u_{j}, \forall j \in \underset{u \in U H E N}{\cup} C_{U H E N u}, j \notin E V
\end{aligned}
$$

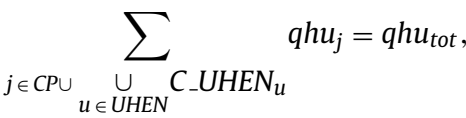

$$
\begin{aligned}
& \sum_{i \in H P \cup} \underbrace{}_{u \in U H E N} C_{-} \text {UHEN }_{u}
\end{aligned}
$$

The variables $q h u_{\text {tot }}$ and $q c u_{\text {tot }}$ denote the total heat duty of the two END-utilities.

(7) Logical constraints on the existence of heat exchangers

These logical constraints link the binary activation variables of the heat exchangers $\left(z_{i j k}\right.$ for matches between process/process, process/HEN-utility and HEN-utility/HEN-utility streams, and $z c u_{i}$ and $z h u_{j}$ for matches between process or HEN-utility with END-utility streams) with the heat which can be transferred (respectively $q_{i j k}, q c u_{i}$ and $q h u_{j}$ ):

$$
\begin{aligned}
& q_{i j k}-\Omega_{i j} * z_{i j k} \leq 0, \forall i \in H O T, \forall j \in C O L D, \forall k \in S T \\
& q c u_{i}-\Omega_{i j} * z c u_{i} \leq 0, \forall i \in H O T \\
& q h u_{j}-\Omega_{i j} * z h u_{j} \leq 0, \forall j \in C O L D .
\end{aligned}
$$

$\Omega_{i j}$ is an upper bound for the heat which can be exchanged between the hot stream $i$ and the cold stream $j$. In order to obtain a tight problem formulation, $\Omega_{i j}$ can be set to the smallest heat content of the two streams involved in the match.

(8) Calculation of approach temperatures and minimum allowed value

These constraints allow to calculate the left and right-hand side approach temperature differences of each heat exchanger which are required to determine the heat transfer area. 
The following constraints are necessary for the left-hand side approach temperature differences:

$$
\begin{aligned}
& d t_{i j k} \leq t_{i, k}-t_{j, k}+\Delta \operatorname{Tmax}_{i j} *\left(1-z_{i j k}\right), \forall k \in S T, \\
& \forall i \in H O T, i \notin C O, \forall j \in C O L D, j \notin E V \\
& d t_{i j k} \leq T c o_{i}-t_{j, k}+\Delta \operatorname{Tmax}_{i j} *\left(1-z_{i j k}\right), \forall k \in S T, \forall i \in C O, \forall j \in C O L D, j \notin E V \\
& d t_{i j k} \leq t_{i, k}-T e v_{j}+\Delta \operatorname{Tmax}_{i j} *\left(1-z_{i j k}\right), \forall k \in S T, \forall i \in H O T, i \notin C O, \forall j \in E V \\
& d t_{i j k} \leq T c o_{i}-T e v_{j}+\Delta \operatorname{Tmax}_{i j} *\left(1-z_{i j k}\right), \forall k \in S T, \forall i \in C O, \forall j \in E V \\
& d t c u_{i} \leq t_{i, N O K+1}-T_{O U U T}+\Delta \operatorname{Tmax}_{i j} *\left(1-z c u_{i}\right), \forall i \in H O T, i \notin C O \\
& d t c u_{i} \leq \operatorname{Tco}_{i}-\operatorname{TOUT}_{C U}+\Delta \operatorname{Tmax}_{i j} *\left(1-z c u_{i}\right), \forall i \in C O
\end{aligned}
$$

The following constraints concern the right-end side temperature differences:

$$
\begin{aligned}
& d t_{i j k+1} \leq t_{i, k+1}-t_{j, k+1}+\Delta \operatorname{Tmax}_{i j} *\left(1-z_{i j k}\right), \forall k \in S T, \\
& \forall i \in H O T, i \notin C O, \forall j \in \operatorname{COLD}, j \notin E V \\
& d t_{i j k+1} \leq T c 0_{i}-t_{j, k+1}+\Delta \operatorname{Tmax}_{i j} *\left(1-z_{i j k}\right), \forall k \in S T, \forall i \in C O, \forall j \in C O L D, j \notin E V \\
& d t_{i j k+1} \leq t_{i, k+1}-T e v_{j}+\Delta \operatorname{Tmax}_{i j} *\left(1-z_{i j k}\right), \forall k \in S T, \forall i \in H O T, i \notin C O, \forall j \in E V \\
& d t_{i j k+1} \leq T c O_{i}-T e v_{j}+\Delta \operatorname{Tmax}_{i j} *\left(1-z_{i j k}\right), \forall k \in S T, \forall i \in C O, \forall j \in E V \\
& d t h u_{j} \leq \operatorname{TOUT}_{H U}-t_{j, 1}+\Delta \operatorname{Tmax}_{i j} *\left(1-z h u_{j}\right), \forall j \in C O L D, j \notin E V \\
& d t h u_{j} \leq \operatorname{TOUT}_{H U}-\operatorname{Tev}_{j}+\Delta \operatorname{Tmax}_{i j} *\left(1-z h u_{j}\right), \forall j \in E V
\end{aligned}
$$

The binary variables are here used to activate the constraints only for the selected heat exchangers (i.e., those with $z_{i j k}=1$ ). $\Delta T$ max $i j$ is the upper bound for the approach temperature difference between hot stream $i$ and cold stream $j$. Since excessively large values penalize the tightness of the problem formulation and damage the effectiveness of the optimization algorithm, $\Delta T \mathrm{max}_{i j}$ is set to the maximum value physically achievable in the HEN, i.e., the difference between the inlet temperature of hot stream $i$ and the inlet temperature of the cold stream $j$.

In order to avoid infinite areas, a positive lower bound $\mathscr{E}_{i j}$ can be specified for each approach temperature difference:

$$
d t_{i j k} \geq \mathscr{E}_{i j} \forall i \in H O T, \forall j \in C O L D, \forall k \in S T \text {. }
$$

(9) No Stream Splitting

In the SYNHEAT superstructure, the no stream splitting condition for a specific subset of streams can be easily included with the following constraint:

$$
\begin{aligned}
& \sum_{j \in C O L D} z_{i j k} \leq 1, \forall i \in S S \cap H O T, \forall k \in S T \\
& \sum_{i \in H O T} z_{i j k} \leq 1, \forall j \in S S \cap C O L D, \forall k \in S T
\end{aligned}
$$

(10) Forbidden matches

For the forbidden matches, the following constraint is included:

$$
z_{i, j, k}=0, \forall(i, j) \in F M, \forall k \in S T
$$

where $F M$ is the set of forbidden matches given as input.

(11) Restricted/required matches

These constraints enable users to impose a minimum or maximum heat exchanged between couples of streams or between one stream and one hot/cold utility. Such constraints can be expressed as:

$$
\begin{aligned}
& \sum_{k \in S T} q_{i j k} \leq \dot{Q}_{\max , i j}, \forall(i, j) \in R M \\
& \sum_{k \in S T} q_{i j k} \geq \dot{Q}_{\min , i j}, \forall(i, j) \in R Q
\end{aligned}
$$

(12) Activation/deactivation of utility streams

Constraints are needed to link the binary activation variables of the utilities with the mass flow rates of the utility streams $\Gamma_{i}$ and the corresponding heat exchangers $z_{i j k} . \Gamma_{\max , i}$ is an upper bound for mass flow rate of the $i$-th utility stream which must be set by the user on the basis of the problem specifications. As an alternative, it could be rigorously determined by using the LP transshipment model proposed 
by Papoulias and Grossmann (1983b). The last two constraints represent the activation of the heat exchangers involving the END-utilities which can exist only provided that the END utilities are selected $\left(y_{h u}=1\right.$ or $\left.y_{c u}=1\right)$.

$$
\begin{aligned}
& \Gamma_{i} \leq y_{u} \cdot \Gamma_{\max , i}, \forall i \in H_{-} \operatorname{UHEN}_{u}, \forall u \in \text { UHEN } \\
& \Gamma_{j} \leq y_{u} \cdot \Gamma_{\max , j}, \forall j \in C_{-} U_{H E N}, \forall u \in U H E N \\
& z_{i j k} \leq y_{u}, \forall k \in S T, \forall i \in H_{-} U_{H E N} \text { and } \forall j \in C_{-} U_{H E N}, \forall u \in U H E N \\
& z c u_{i} \leq y_{u}, \forall i \in H_{-} \operatorname{UHEN}_{u}, \forall u \in \text { UHEN } \\
& z h u_{j} \leq y_{u}, \forall j \in C_{-} \operatorname{UHEN}_{u}, \forall u \in \text { UHEN } \\
& z c u_{i} \leq y_{c u}, \forall i \in H O T \\
& z h u_{j} \leq y_{h u}, \forall j \in C O L D
\end{aligned}
$$

(13) Specific constraints for complex utilities

Specific constraints may be added in order to model complex utilities, characterized by a superstructure and multiple streams. Such constraints relate the mass flow rates and inlet/outlet temperatures of the streams of a certain utility system and also put them in relation with the costs (investment and operation) and the useful effects (e.g., generated power) of the utility. As an example, the optimal design problem of a heat recovery steam cycle with multiple pressure levels of evaporation can be formulated as a non-convex nonlinear program (NLP), as shown in Martelli et al. (2011a,b). In the same work, the authors show that the nonlinearities of the constraints can be avoided by fixing the pressures and temperatures of the streams and avoiding non-isothermal mixing processes so that the enthalpies of the streams at the inlet/outlet of the components are fixed. In this case, not only the mass balance equations but also the energy balance equations of the cycle components are linear with respect to the steam/water mass flow rates.

Thus, if the evaporation pressures, condenser pressure, and superheat temperature of steam are fixed, and the isothermal mixing assumption can be made without major limitations of the cycle design options, the steam cycle model is reduced to a set of linear constraints with respect to the steam/water mass flow rates:

$$
\begin{gathered}
\sum_{i \in H_{-} U H E N_{u} \cup C_{-} U H E N_{u}}\left(a_{i, l} \Gamma_{i}\right)=0 \forall l \in \mathrm{C}_{u}, \\
\sum_{i \in H_{\text {UHEN } u} \cup C_{-} U_{H E N}}\left(a_{i, l} h_{i} \Gamma_{i}\right)+\text { qin }_{l}-\text { pout }_{l}=0 \forall l \in C_{u}
\end{gathered}
$$

where $C_{u}$ denotes the set of components (turbine sections, pumps, mixers, drums, headers, etc.) of the utility system $u$, and the coefficients $a_{i, l}$ can assume value -1 if the stream exit the component, 0 if the stream does not enter or exit the component or 1 if the stream enters the component. The parameter $h_{i}$ is the total enthalpy of the stream while qin is $_{l}$ the thermal power and pout $t_{l}$ is the output mechanical power of the cycle component $l$.

If the cycle has multiple evaporation levels $e$, it is possible to activate/deactivate each of them by introducing the binary variables $y_{u, e}$ :

$$
\begin{aligned}
& \Gamma_{i} \leq y_{u, e} \Gamma_{\max , i} \\
& z_{i j k} \leq y_{u, e}
\end{aligned}
$$

Of course, the variables associated to the pressure levels must be subordinate to the activation of the overall utility system $y_{u}$ :

$$
y_{u, e} \leq y_{u}
$$

It is worth noting that similar equations can be written to model other complex utilities such as organic Rankine cycles, heat pumps and refrigeration cycles.

If the evaporation pressures, condenser pressure, and superheat temperature of steam cycle are optimization variables and nonisothermal mixing can occur between different steam flows, the enthalpies $h_{i}$ become nonlinear functions of the steam pressures and temperatures. Thus, Eq. (14) become a nonlinear noncovex equality constraint.

In this first work, the evaporation pressures, condenser pressure, and superheat temperatures of the steam cycle are fixed and the isothermal mixing assumption is made for the steam cycle streams. The optimization of the stream temperatures and pressures, as well as the possibility of having non-isothermal mixing between utility streams within their superstructures, will be analyzed in a subsequent work.

If the cycle pressures and temperatures are fixed, the investment cost $i c_{u}$ of the utility system $u$ can be expressed as functions of the activated pressure levels $y_{u, e}$, the stream mass flow rates $\Gamma_{i}$, the heat input qin $l$ and power output pout $t_{l}$ of the components:

$$
i c_{u}\left(y_{u, e}, \Gamma_{i}, \text { qin }_{l}, \text { pout }_{l}\right)=\sum_{e \in U H E N u} f c_{C U, e} y_{u, e}+v c\left(\Gamma_{i}, \text { qin }_{l}, \text { pout }_{l}\right)
$$

where $f c_{C U, e}$ denotes the activation cost of pressure level $e$, and $v c$ denotes the nonlinear function of the variable investment costs. This function is generally nonlinear due to the economies of scales in the manufacturing process of the equipment units. It is important to note that $i c_{u}$ does not include the cost of the heat exchangers of the utility as these are accounted in the cost of the HEN.

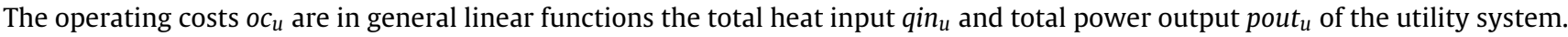




\subsection{Objective function}

For the optimization problem, the most relevant objective function is the total annual cost of the integrated systems comprising heat exchanger network and utility systems, which can be written as:

$$
\begin{aligned}
& \text { minimize : } \\
& \sum_{u \in U H E N}\left[i c_{u}\left(y_{u, e}, \Gamma_{i}, \text { qin }_{l}, \text { pout }_{l}\right)+o c_{u}\left(q i n_{u}, \text { pout }_{u}\right)\right]+ \\
& +\left[i c_{c u}\left(y_{c u}, q c u_{t o t}\right)+o c_{c u}\left(q c u_{t o t}\right)\right]+\left[i c_{h u}\left(y_{h u}, q h u_{t o t}\right)+o c_{h u}\left(q h u_{t o t}\right)\right]+ \\
& +\sum_{i \in H O T j} \sum_{C O L D k \in S T} \sum_{F C_{i j}} * z_{i j k}+ \\
& +\sum_{i \in H O T} F C_{C U, i} * z c u_{i}+\sum_{j \in C O L D} F C_{H U, j} * z h u_{j}+ \\
& +\sum_{i \in \text { HOT }} \sum_{j \in C O L D} \sum_{k \in S T} C_{i j}\left(\frac{q_{i j k}}{U_{i j} * L M T D_{i j k}}\right)^{B_{i j}}+ \\
& +\sum_{i \in H O T} C_{C U, i}\left(\frac{q c u_{i}}{U_{C U, i} * L M T D_{i, C U}}\right)^{B_{C U, i}}+\sum_{j \in C O L D} C_{H U, j}\left(\frac{q h u_{j}}{U_{H U, j} * L M T D_{H U, j}}\right)^{B_{H U, j}}
\end{aligned}
$$

In Eq. (19), $i c_{c u}\left(y_{c u}, q c u_{t o t}\right)$ and $o c_{c u}\left(q c u_{t o t}\right)$ label the investment and operating costs of the cold-end utility, while $i c_{h u}\left(y_{h u}, q h u_{t o t}\right)$ and $o c_{h u}\left(q h u_{t o t}\right)$ denote the hot utility. $F C_{i j}, F C_{C U, i}$ and $F C_{H U, i}$ are input parameters and represent the fixed activation costs of the heat exchangers between streams. $C_{i j}, C_{C U, i}$ and $C_{H U, i}$ are specific area costs. In general, different costs can be defined for each couple of stream. LMTD labels the $\log$ mean temperature difference (LMTD) between hot stream $i$ and cold stream $j$ in stage $k$ :

$$
L M T D_{i j k}=\frac{d t_{i j k}-d t_{i j k+1}}{\ln \left(\frac{d t_{i j k}}{d t_{i j k+1}}\right)}
$$

However, when the temperature differences $d t_{i j k}$ and $d t_{i j k+1}$ take the same value (such as when the heat exchanger at stage $k$ is not activated in the superstructure.), the LMTD equation leads to an indeterminate form $0 / 0$. In order to avoid numerical problems, the approximation proposed by (Chen, 1987) is used for the LMTD terms:

$$
L M T D_{i j k} \approx\left(d t_{i j k} * d t_{i j k+1} * \frac{d t_{i j k}+d t_{i j k+1}}{2}\right)^{1 / 3}
$$

where $d t_{i j k}$ represent the approach temperatures for exchanger $(i, j)$ in stage $k$.

Selection of the number of stages NOK

According to Yee and Grossmann (1990), the number of stages has been set to

$$
\mathrm{NOK}=\max \left\{N_{H}, N_{c}\right\}+1
$$

where $N_{H}$ and $N_{C}$ are respectively the number of hot and cold streams, of both process and utility systems, involved in the heat exchanger network. The value in Eq. (22) corresponds to the situation, takes as limit, in which a certain stream has one match with all the other streams. It is a reasonable upper bound on the number of required stages since a stream does not typically have multiple matches with each of the other streams. However, nothing prevents setting higher values for stage number.

\section{Two-stage algorithm}

The MINLP problem presented in Section 3 is more challenging than those arising with the classic HEN SYNHEAT superstructure (Yee and Grossmann, 1990) due to the nonconvexity of the energy balance constraints of the stages (Eq. (3)). Indeed such constraints include bilinear terms, i.e., products between utility mass flow rates $\Gamma_{i}$ and stage temperatures $t_{i, k}$. This makes general-purpose spatial branch and bound algorithms (in theory ideally suited for nonconvex MINLPs) less effective. Indeed, as shown by the computational results reported in Section 6.1, within the time limit of 25,000 s BARON (Tawarmalani and Sahinidis, 2005) version 17.1.2 (currently one of the best general purpose MINLP solver for nonconvex problems) finds a suboptimal solution even on a small scale literature test problem. Besides, the large optimality gap (i.e., difference between the best feasible solution found and the lower bound found by solving relaxed linear subproblems) suggests that a significantly longer computational time would be required to reach convergence.

In this work, a two-stage algorithm is specifically developed by adapting and extending the approach proposed by Chen et al. (2008) for the synthesis of HENs.

The basic idea of Chen et al. (2008) is to tackle the MINLP related to the "SYNHEAT temperature-stage" superstructure with a twostage algorithm in which, at the upper level, the integer variables are optimized with a Nested Tabu Search algorithm (a meta-heuristic algorithm (Dréo et al., 2006)), while, at the lower level, the real variables are optimized with the Sequential Quadratic Programming (SQP) algorithm. The authors found a systematic approach to reformulate the NLP depending on the integer solution passed by the upper level Nested Tabu Search. Thanks to the problem reformulation, the NLP does not have linearly dependent constraints and fewer variables and constraints. Despite the heuristic nature of the upper level algorithm, the two-stage algorithm finds the best-known optimal solutions for all the considered test cases. It is worth noting that the work of Chen et al. (2008) is limited to the optimization of just the HEN (i.e., utility systems are not optimized). 
In this work, the idea of Chen et al. (2008) is adapted and extended to cope with the MINLP problem described in Section 3 (including also the optimization of utility systems). At the upper level the Variable Neighbourhood Search (VNS) algorithm of Egea et al. (2014) optimizes the binary variables (dealing with a black-box integer problem), while at the lower level the Sequential Quadratic Programming algorithm of SNOPT (Gill et al., 2005) optimizes the real variables coping with the nonconvex constraints.

The NLP model replicates the MINLP model, described in Section 3, at the exception of the integer variables, which become parameters taken from the upper level. In order to minimize the variables and constraints of the lower-level Non-Linear Program (NLP), the adaptive reformulation strategy of Chen et al. (2008) has been extended so as to deal with not only the HEN, but also utility systems. Given the combination of binary variables set by the VNS algorithm, when formulating the NLP, the variables and constraints related to the inactive utility systems and heat exchangers are removed. When considering integrated utility streams (those in UHEN), the lower level NLP features bilinear constraints associated to the products between mass flow rates and stage temperatures $\left(t_{i, k}-t_{i, k+1}\right) * \Gamma_{i}$ which make the NLP problem more challenging to solve. Indeed, while the NLP problem tackled by Chen et al. (2008) for the synthesis of the HEN without integrated utility has linear constraints and the nonlinearity only in the objective function, the NLP problem of this work features also non-convex nonlinear (bilinear) constraints which increases the risk of finding local minima.

The decomposed problem can be formally stated as follows:

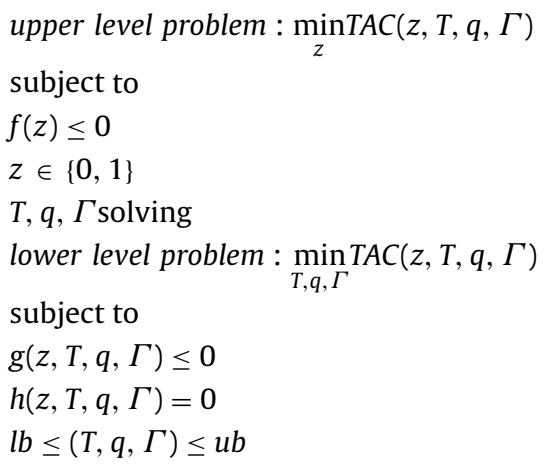

where the objective function of both levels is the total annual cost (TAC) which depends on the optimization variables $\boldsymbol{z}, \boldsymbol{T}, \boldsymbol{q}, \boldsymbol{\Gamma}$ (selection of heat exchangers and utility, temperatures, mass flow rates of utilities). $\boldsymbol{f}$ denotes the constraints on the integer variables such as no stream splitting constraints, forbidden matches, forced matches, etc. $\boldsymbol{l} \boldsymbol{b}$ and $\boldsymbol{u b}$ denote the lower and upper bounds on the decision variables, while $\boldsymbol{g}$ and $\boldsymbol{h}$ denote respectively the set of inequality and equality constraints corresponding to the model equations of the HEN. In the lower level the values of the binary variables corresponding to the selection of the heat exchangers and utility systems are fixed, while $\boldsymbol{T}$, $\boldsymbol{q}, \boldsymbol{\Gamma}$ are optimized. Since the objective function as well as the constraints are nonlinear nonconvex with respect to the decision variables, the optimization problem is a nonconvex NonLinear Program (NLP).

\subsection{Upper level problem: integer programming algorithm}

The upper level problem is solved using the Variable Neighborhood Search (VNS) algorithm proposed by Egea et al. (2014). The VNS algorithm is a trajectory-based metaheuristic method, which performs local search and evaluates the objective function in a neighborhood of a starting solution. The search algorithm iterates the procedure and locates different local optima, then it selects the best one and generates the new neighborhood by perturbing the decision variables. The formulation of Egea et al. (2014) is chosen because it proposes an improved, distance-based, strategy to generate new neighborhoods. This allows to avoid repeating cycles in the search and to increase the efficiency of the algorithm when considering large-scale problems. Additionally, the "go-beyond" heuristic strategy for continuous optimization originally proposed in Egea et al. (2014) has been adapted in order to increase the algorithm efficiency during the local search. The VNS algorithm is freely available in the MEIGO optimization toolbox as a Matlab code (Egea et al., 2014). The stopping criterion is the number of maximum objective function evaluations.

Since the VNS algorithm cannot directly handle constraints, the set of inequality constraints of the upper level problem $(\boldsymbol{f}(\boldsymbol{z}) \leq 0)$ is handled with the penalty approach (i.e., by penalizing the quadratic violation of the constraint).

\subsection{Lower level problem: adaptive reformulation of the NLP problem}

This formulation allows to simplify the lower level NLP, given the binary values of the activation of utility streams and heat exchangers fixed at the upper level by the IP algorithm at each iteration. Heat exchangers and utility are divided into two subsets, the subset of active units (denoted by the prefix "A": AH_UHEN, AC_UHEN, etc.) and the set of inactive units (denoted by the prefix "I") based on the value of the corresponding binary activation variable. The basic idea of the adaptive reformulation is to keep only the variables and constraints related to the selected units. As far as variables are concerned, $q_{i j k}$ is defined only for the selected heat exchangers, $q c u_{i}$ and $q h u_{j}$ only for the streams with active UEND utilities, $t_{i, k}, t_{j, k}$ and $\Gamma_{i}$ only for the selected utility in UHEN. As for constraints, heat balance equations are written only for the active streams (process streams and selected utility streams) and active stages (Eq. (25)). For inactive stages, the energy balance equation can be avoided by imposing the equality between inlet and outlet temperatures $\left(t_{i, k}=t_{i, k+1}\right)$, as written in Eq. $(27)$.

Additional sets (with respect to the MINLP problem):

$$
\begin{aligned}
& Z=\{(i, j, k) \mid(i, j) \notin F M\} \\
& A U=\left\{u \mid u \text { is an activated U_HEN utility, with } \bar{y}_{u}=1\right\}
\end{aligned}
$$


$A_{-} U_{H E N}=\left\{i \mid i\right.$ is an activated hot stream of utility $u$, with $\left.\sum_{j \in C P k \in S T} \sum_{i j k} \geq 1, i \in H_{-}{ }^{U H E N} N_{u}\right\}$

$A C_{-} U_{H E N}=\left\{j j\right.$ is an activated cold stream of utility $u$, with $\left.\sum_{i \in H P k \in S T} \sum_{\bar{z}_{i j k}} \geq 1, j \in C_{-} U H E N_{u}\right\}$

$A H O T=\{i \mid i$ is a hot process or an activated utility stream $\}=H P \cup \underset{u \in U}{\cup} A_{-} H_{-} H E N_{u}$

$A C O L D=\{j \mid j$ is cold process or an activated utility stream $\}=C P \cup \underset{u \in U}{\cup} A C_{-} U H E N_{u}$

$A H U=\left\{j \mid\right.$ the match between hot UEND utility and cold stream $j$ is activated, with $\left.\overline{z h u}_{j}=1, j \in A C O L D\right\}$

$A C U=\left\{i \mid\right.$ the match between cold UEND utility and hot stream $i$ is activated, with $\left.\overline{z c u}_{i}=1, i \in A H O T\right\}$

$A H X=$ set of active heat exchangers $=\left\{(i, j, k) \mid \bar{z}_{i j k} \geq 1, i \in A H O T, j \in A C O L D, k \in S T\right\}$

Additional parameters (with respect to the MINLP problem):

$\bar{z}_{i j k}=$ binary parameter to denote the activation of the match $(i, j)$ in stage $k,(i, j, k) \in Z$

$\overline{z c u}_{i}=$ binary parameter to denote the activation of the heat exchanger between the cold UEND utility and hot stream i

$\overline{z h u}_{j}=$ binary parameter to denote tthe activation of the heat exchanger between the hot UEND utility and cold stream $\mathrm{j}$

$\bar{y}_{u}=$ binary parameter to denote the activation of UHEN utility $u$

$q h u_{M A X}=$ maximum a mount of heat available at the hot UEND utility

$q c u_{M A X}=$ maximum amount of heat available at the cold UEN Dutility

$\mathscr{E}_{i j}=$ minimum temperature difference for the match $(i, j)$

Decision variables

$q_{i j k}=$ heat exchanged between hot stream $i$ and cold stream $j$ in stage $k,(i, j, k) \in A H X$

$q c u_{i}=$ heat exchanged between hot stream $i$ and cold end utility, $i \in$ AHOT

$q h u_{j}=$ heat exchanged between hot end utility and cold stream $j, j \in A C O L D$

$t_{i, k}=$ temperature of non - isothermal hot stream $i$ at hot end of stage $k, i \in A H O T, i \notin C O$

$t_{j, k}=$ temperature of non - is othermal cold stream $j$ at hot end of stage $k, j \in A C O L D, j \notin E V$

$\Gamma_{i}=$ flow rate ofutility stream $i, i \in A_{-} U H E N_{u}$ or $i \in A C_{-} U H E N_{u}$

Constraints:

(1) Positivity of heat exchanged variables:

$q_{i j k} \geq 0, \forall(i, j, k) \in A H X$

(2) Overall heat balance for each isothermal process and UHEN utility stream

$$
\begin{aligned}
& F_{i} * \lambda_{i}=\sum_{(j, k)((i, j, k) \in A H X} q_{i j k}+q c u_{i}, \forall i \in H P \cap C O \\
& F_{j} * \lambda_{j}=\sum_{(i, k) \mid(i, j, k) \in A H X} q_{i j k}+q h u_{j}, \forall j \in C P \cap E V \\
& \Gamma_{j} * \lambda_{j}=\sum_{(i, k) \mid(i, j, k) \in A H X} q_{i j k}+q h u_{j}, \forall j \in \underbrace{\cup}_{u \in U H E N} A C_{-} U_{H} H_{L} \cap E V
\end{aligned}
$$


(3) Heat balance at each activated stage

$$
\begin{aligned}
& \left(t_{i, k}-t_{i, k+1}\right) * F_{i} * C p_{i}=\sum_{j \mid(i, j, k) \in A H X} q_{i j k}, \forall(i, k) \mid \sum_{j \in A C O L D} \bar{z}_{i j k} \geq 1, i \in H P, i \notin C O, k \in S T \\
& \left(t_{j, k}-t_{j, k+1}\right) * F_{j} * C p_{j}=\sum_{i(i, j, k) \in A H X} q_{i j k}, \forall(j, k) \mid \sum_{i \in A H O T} \bar{z}_{i j k} \geq 1, j \in C P, j \notin E V, k \in S T \\
& \left(t_{i, k}-t_{i, k+1}\right) * \Gamma_{i} * C p_{i}=\sum_{j \mid(i, j, k) \in A H X} q_{i j k}, \\
& \forall u \in A U, \forall(i, k) \mid \sum_{j \in A C O L D} \bar{z}_{i j k} \geq 1, i \in A H_{U H E N u}, i \notin C O, k \in S T \\
& \left(t_{j, k}-t_{j, k+1}\right) * \Gamma_{j} * C p_{j}=\sum_{i \mid(i, j, k) \in A H X} q_{i j k}, \\
& \forall u \in A U, \forall(j, k) \mid \sum_{i \in A H O T} \bar{z}_{i j k} \geq 1, j \in A C_{U H E N u}, j \notin E V, k \in S T
\end{aligned}
$$

(4) Assignment of superstructure inlet temperatures

$$
\begin{aligned}
& \operatorname{TIN}_{i}=t_{i, 1}, \forall i \in A H O T, i \notin C O \\
& \operatorname{TIN}_{j}=t_{j, N O K+1}, \forall j \in A C O L D, j \notin E V
\end{aligned}
$$

(5) Feasibility of temperatures

$$
\begin{aligned}
& t_{i, k} \geq t_{i, k+1}, \forall(i, k) \mid \sum_{j \in A C O L D} \bar{z}_{i j k} \geq 1, i \in A H O T, i \notin C O, k \in S T \\
& t_{i, k}=t_{i, k+1}, \forall(i, k) \sum_{j \in A C O L D} \bar{z}_{i j k}=0, i \in A H O T, i \notin C O, k \in S T \\
& t_{j, k} \geq t_{j, k+1}, \forall(j, k) \mid \sum_{i \in A H O T} \bar{z}_{i j k} \geq 1, j \in A C O L D, k \in S T, j \notin E V \\
& t_{j, k}=t_{j, k+1}, \forall(j, k) \mid \sum_{i \in A H O T} \bar{z}_{i j k}=0, j \in A C O L D, k \in S T, j \notin E V \\
& \text { TOUT }_{i} \leq t_{i, N O K+1}, \forall i \in A C U, i \notin C O \\
& \text { TOUT }_{i}=t_{i, N O K+1}, \forall i \in A H O T, i \notin A C U, i \notin C O \\
& \text { TOUT }_{j} \geq t_{j, 1}, \forall j \in A H U, j \notin E V \\
& \text { TOUT }_{j}=t_{j, 1}, \forall j \in A C O L D, j \notin A H U, j \notin E V
\end{aligned}
$$

(6) Balances of active heat exchangers of UEND utilities

$$
\begin{aligned}
& \left(t_{i, N O K+1}-T_{O U T}\right) * F_{i}=q c u_{i}, \forall i \in A C U \cap H P, i \notin C O \\
& \left(T_{O U U T}-t_{j, 1}\right) * F_{j}=q h u_{j}, \forall j \in A H U \cap C P, j \notin E V \\
& \left(t_{i, N O K+1}-T_{O U T}\right) * \Gamma_{i}=q c u_{i}, \forall i \in A C U \cap \underset{u \in U H E N}{\cup} H_{U H E N u}, i \notin C O \\
& \left(\text { TOUT }_{j}-t_{j, 1}\right) * \Gamma_{j}=q h u_{j}, \forall j \in A H U \cap \underset{u \in U H E N}{\cup} C_{U H E N u}, j \notin E V
\end{aligned}
$$

(7) Logical constraints: not required

(8) Calculation of approach temperatures Hot side:

$$
\begin{aligned}
& \mathscr{E}_{i j} \leq t_{i, k}-t_{j, k}, \forall(i, j, k) \in A H X, i \notin C O, j \notin E V \\
& \mathscr{E}_{i j} \leq T c o_{i}-t_{j, k}, \forall(i, j, k) \in A H X, i \in C O, j \notin E V \\
& \mathscr{E}_{i j} \leq t_{i, k}-T e v_{j}, \forall(i, j, k) \in A H X, i \notin C O, j \in E V \\
& \mathscr{E}_{i j} \leq t_{i, N O K+1}-\operatorname{TOUT}_{C U}, \forall i \in A C U, i \notin C O
\end{aligned}
$$

Cold side:

$$
\begin{aligned}
& \mathscr{E}_{i j} \leq t_{i, k+1}-t_{j, k+1}, \forall(i, j, k) \in A H X, i \notin C O, j \notin E V \\
& \mathscr{E}_{i j} \leq T c o_{i}-t_{j, k+1}, \forall(i, j, k) \in A H X, i \in C O, j \notin E V \\
& \mathscr{E}_{i j} \leq t_{i, k+1}-T e v_{j}, \forall(i, j, k) \in A H X, i \notin C O, j \in E V \\
& \mathscr{E}_{i j} \leq \operatorname{TOUT}_{H U}-t_{j, 1}, \forall j \in A H U, j \notin E V
\end{aligned}
$$


(9) Restricted/required matches

$$
\begin{aligned}
& \sum_{k \in S T} q_{i j k} \leq \dot{Q}_{\max , i j}, \forall(i, j) \in R M \\
& \sum_{k \in S T} q_{i j k} \geq \dot{Q}_{\min , i j}, \forall(i, j) \in R Q
\end{aligned}
$$

(10) Constraints on active UHEN utility streams

$$
\begin{aligned}
& \Gamma_{i} \leq \Gamma_{\text {max }, i}, \forall i \in A H_{-} U H E N_{u}, \forall u \in A U \\
& \Gamma_{j} \leq \Gamma_{\text {max }, j}, \forall j \in A C_{-} H_{H E N}, \forall u \in A U
\end{aligned}
$$

(11) Specific constraints for complex utilities: same equations as the MINLP problem, Eqs. (13) - (18).

(12) Maximum use of UEND utilities

$$
\begin{aligned}
& \sum_{i \in A C U} q c u_{i} \leq q c u_{M A X} \\
& \sum_{j \in A H U} q h u_{j} \leq q h u_{M A X}
\end{aligned}
$$

Objective function:

$$
\begin{aligned}
& \sum_{u \in A U i \in A H_{-} U H E N_{u}}^{\operatorname{minimize~:~}} P C_{i} * \Gamma_{i}+\sum_{u \in A U j \in A C_{-} U H E N_{u}} \sum_{j \in A C U} P C_{j} * \Gamma_{j}+ \\
& +\sum_{C U, i} * q C u_{i}+\sum_{j \in A H U} C_{H U, j} * q h u_{j}+ \\
& +\sum_{(i, j, k) \in A H X} C_{i j}\left(\frac{q_{i j k}}{U_{i j} * L M T D_{i j k}}\right)^{B_{i j}}+ \\
& +\sum_{i \in A C U} C_{C U, i}\left(\frac{q c u_{i}}{U_{C U, i} * L M T D_{i, C U}}\right)^{B_{C U, i}}+\sum_{j \in A H U} C_{H U, j}\left(\frac{q h u_{j}}{U_{H U, j} * L M T D_{H U, j}}\right)^{B_{H U, j}}
\end{aligned}
$$

As previously motivated, constraints (23-33) define a nonconvex nonlinear NLP. The selection of the lower level optimizer was carefully evaluated by comparing several commercial NLP optimizers: SNOPT (employing a sparse SQP algorithm with limited-memory quasiNewton approximations to the Hessian of Lagrangian), effective for problems with a nonlinear objective function and large numbers of sparse linear constraints, as indicated by Gill et al. (2005), KNITRO (a software package employing interior points and active set/SQP algorithms for NLP proposed by (Byrd et al., 2006)), IPOPT (an interior point algorithm for large scale NLP proposed by Watcher and Biegler, (2005)), MINOS (using a projected Lagrangian method, where a sequence of sub problems with linearized constraints and augmented Lagrangian objective, (Murtagh and Saunders, 1983)), CONOPT (feasible path solver based on generalized reduced gradient method, (Drud, 1992)), SCIP (Gamrath et al., 2016) and BARON (Tawarmalani and Sahinidis, 2005) (spatial branch and bound solvers for nonconvex NLP and MINLP). Preliminary computational results on well-known test problems of HEN synthesis indicated that SCIP and BARON, although specifically suited for nonconvex problems, require a too long computational time (of the order of 10-20 min) to reach sufficiently low optimality gaps. The long computation time makes it prohibitive to use these global solvers since the lower-level NLP needs to be solved thousands of times. Among the local NLP solvers, SNOPT performs on average better than the others in terms of robustness (returning for each test problem either optimal or close-to-optimal solutions), solution quality (constraint violation and value of the objective function) and computational time ( $<1 \mathrm{~s}$, also on problems with 20 and more streams). Being the NLP nonconvex, the risk of finding local minima is limited by defining tight upper and lower bounds on the variables, and by providing a good starting point. Indeed, first-guess values of the utility mass flow rates in UHEN (key nonlinear optimization variable leading to the bilinear terms of the NLP) are computed with the sequential initialization procedure described in the next section and their values can be passed to SNOPT as starting values.

\section{MILP initialization model}

In order to reduce the computational time required for the convergence of the upper-level integer programming algorithm, an ad hoc sequential solution initialization procedure has been developed (see Fig. 5).

First, the energy targeting method of Marechal and Kalitventzeff $(1998,1999)$ is applied to provide a first estimate of the optimal selection of utility systems, their configuration, and the mass flow rates of their streams by minimizing a linear approximation of the total annual utility cost (operation and investment cost of utility systems). The energy targeting method essentially includes the utility models with variable stream mass flow rates and binary activation variable in the "LP transshipment" model originally proposed by Papoulias and Grossmann (1983b) to formulate the heat cascade at the basis of Pinch Analysis as a Mixed Integer Linear Program. Thanks to the rigorous mathematical representation of the transshipment model, forbidden and forced matches can be easily included. Thus, the energy targeting method of Marechal and Kalitventzeff $(1998,1999)$ allows to optimize the utility selection, configuration and mass flow rates for the best plant heat integration (process + utility systems) by solving a MILP with a limited number of binary variables (just one per each utility system or utility configuration). Key input data for the heat integration methodology are the heat recovery approach temperature contributions $\left(H R A T_{\mathrm{i}}\right)$ of the streams used to define the temperature intervals (which may be different for each stream so as to take into account the heat transfer coefficient). When defining the temperature intervals of the heat cascade, the temperatures of hot stream $i$ are shifted down of $H R A T_{\mathrm{i}} / 2$ while those of cold stream $\mathrm{j}$ are shifted up of $H R A T_{\mathrm{j}} / 2$. As a result, within the heat cascade, hot stream $i$ can exchange 


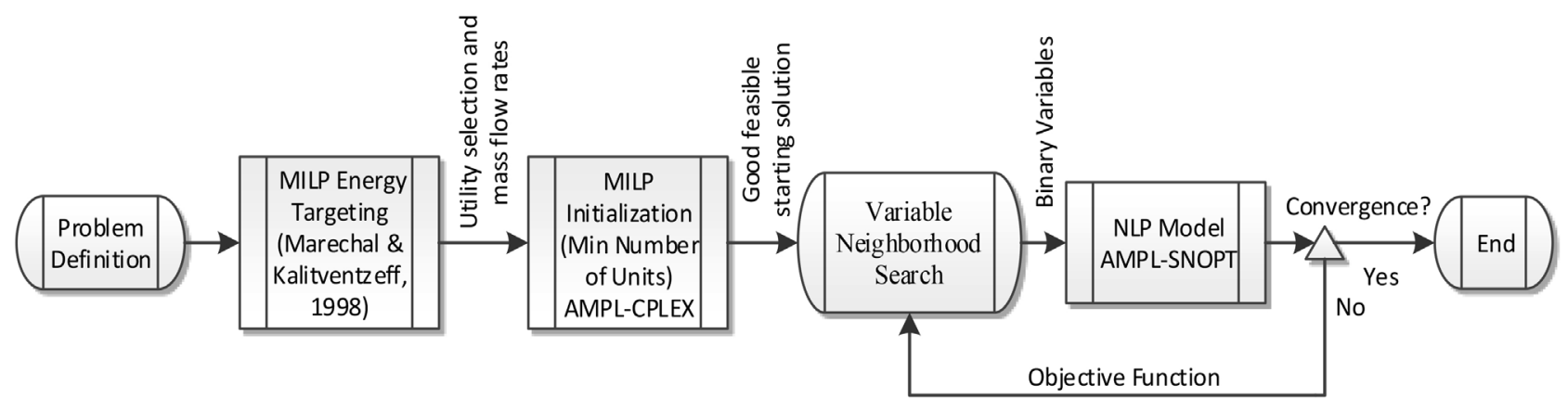

Fig. 5. Block flow diagram of the two-stage algorithm with initialization.

heat with a cold stream $j$ if the temperature difference is larger than $H R A T_{\mathrm{i}} / 2+H R A T_{\mathrm{j}} / 2$. As a general rule, streams with low heat transfer coefficients (e.g., gas) should have high $H R A T / 2\left(15-20^{\circ} \mathrm{C}\right)$ while streams with high heat transfer coefficients (e.g., liquid or boiling water) can have small values $\left(2.5-5^{\circ} \mathrm{C}\right)$. It is worth noting that such values need to be just preliminary guesses as they will be corrected properly considering the actual HX costs in the two-stage MINLP algorithm.

Once the utility selection and mass flow rates are found, a first configuration of the HEN is determined by including the selected utility streams and the process streams in a linearized version of SYNHEAT HEN superstructure of Yee and Grossmann (1990) and minimizing the number of heat exchangers. Since the utility flow rates are fixed and the objective function (number of heat exchangers) does not contain any nonlinear term, this initialization optimization problem is linear (i.e., a MILP), then considerably easier to solve compared to the original MINLP. The MILP model replicates the MINLP model with the exception that the utility flow rates are fixed and the objective function is to minimize the weighted number of heat exchangers, or weighted matches. However, on large scale problems, a large branch-and-bound gap (e.g., 10\%) may be necessary to avoid excessive computational times. In order to speed up the convergence rate of the MILP solver (CPLEX), different penalty levels $p_{i j}$ are assigned to matches $(i, j)$ depending on estimates of their costs or on match priorities, as in Elia et al. (2010). For example these penalty levels $p_{i j}$ can be set according to engineering criteria which include technical and economical factors such as the distance between the two streams $(i, j)$ in the plant, the expected cost of the heat exchanger, the expected operational issues, etc. The objective function is the minimization of the sum of the weights of all matches. Moreover, differently from the MINLP problem, since the area cost is not considered in the MILP, lower bounds for the temperature differences associated to the matches $(i, j)$ must be defined: $d t_{i j k} \geq \Delta \operatorname{Tmin}_{i j}$. Such bounds can be defined according to engineering design criteria based on the type of heat exchanger design and type of fluid (e.g., $10^{\circ} \mathrm{C}$ for gas-liquid heat exchangers, $5^{\circ} \mathrm{C}$ for liquid-liquid heat exchangers, $30^{\circ} \mathrm{C}$ for gas-gas heat exchanger, etc.).

It is important to note that the HEN initialization MILP (linearized version of SYNHEAT HEN) may turn out to be infeasible for one of the following issues:

1. Too high $\Delta \operatorname{Tmin}_{i j}$ have been specified compared to the value of the total heat recovery approach temperature between the streams $\left(H R A T_{\mathrm{i}} / 2+H R A T_{\mathrm{j}} / 2\right)$ considered in the energy targeting optimization. In this case, either $\Delta \operatorname{Tmin}_{i j}$ must be decreased or the energy targeting must be repeated with larger values of $H R A T / 2$.

2. The number of stages set for the HEN superstructure is limited compared to the number of stages required to reproduce the heat integration solution identified by the energy targeting methodology. To this aim, it is important to note than the energy targeting methodology based on the heat cascade is essentially equivalent to a HEN superstructure employing a number of stages (with multiflow heat exchangers allowing heat transfer from the hot streams to the cold streams existing in the temperature interval) equal to the number of intervals of the heat cascade. In this case, either the number of HEN stages must be increased (but this leads to a considerable growth of the computational time) or the energy targeting must be repeated with larger values of HRAT/2 (so that a lower utility cost target is found which can be achieved with a the current HEN superstructure without increasing the number of stages).

3. In the MILP problem, some of the streams are subject to the no stream splitting constraint. In this case, either the number of HEN stages must be increased or the energy targeting must be repeated with larger values of $H R A T / 2$.

Starting from the solution identified by the sequential initialization procedure, the VNS algorithm improves the selection/configuration of utility systems and heat exchangers with a considerable saving of computational time compared to the use of a random starting point.

It is worth noting that the initialization procedure exploits not only mathematical expedients but also engineering knowledge (e.g., in the definition of the HRAT/2, $\Delta \operatorname{Tmin}_{i j}$ and penalties of the matches) to find a good starting solution. Thus, the quality of the solution depends also on the know-how of the user.

\section{Test cases}

The algorithm has been tested on several test cases including literature HEN synthesis problems and real-world power plant design problems. Here we report the most interesting test cases: (a) a literature test case with multiple utilities taken from Isafiade and Fraser (2008), (b) the optimization of a triple-pressure-level Heat Recovery Steam Cycle (HRSC), including the HRSG and the steam cycle, of a natural gas fired combined cycle, and (c) the optimization of an Integrated Gasification Combined Cycle.

\subsection{Literature test case}

The method has been tested on a literature test case with multiple utilities taken from Isafiade and Fraser (2008). The example has two hot and three cold process streams, and three hot and two cold utilities. The data are reported in Table 1. In our superstructure, the utility 
Table 1

Process and utility stream data of the test problem from Isafiade and Fraser (2008).

\begin{tabular}{|c|c|c|c|}
\hline Process stream & $\mathrm{F}[\mathrm{kW} / \mathrm{K}]$ & $\mathrm{T}_{\mathrm{IN}}\left[{ }^{\circ} \mathrm{C}\right]$ & $\mathrm{T}_{\text {OUT }}\left[{ }^{\circ} \mathrm{C}\right]$ \\
\hline $\mathrm{H} 1$ & 150 & 155 & 85 \\
\hline $\mathrm{H} 2$ & 85 & 230 & 40 \\
\hline $\mathrm{C} 1$ & 140 & 115 & 210 \\
\hline $\mathrm{C} 2$ & 55 & 50 & 180 \\
\hline $\mathrm{C} 3$ & 60 & 60 & 175 \\
\hline Utility streams & $\mathrm{T}_{\mathrm{IN}}\left[{ }^{\circ} \mathrm{C}\right]$ & $\mathrm{T}_{\text {OUT }}\left[{ }^{\circ} \mathrm{C}\right]$ & Cost [\$/kWy] \\
\hline HPS & 255 & 255 & 70 \\
\hline MPS & 205 & 205 & 50 \\
\hline LPS & 150 & 250 & 20 \\
\hline AC & 40 & 60 & 5 \\
\hline CW & 30 & 40 & 10 \\
\hline
\end{tabular}

Annualization factor $(C C R)=0.322 / y$;

Exchanger capital cost $\left[\$ / \mathrm{m}^{2}\right]=13000+1000 *$ Area $\left[\mathrm{m}^{2}\right] \hat{0} .83$.

Table 2

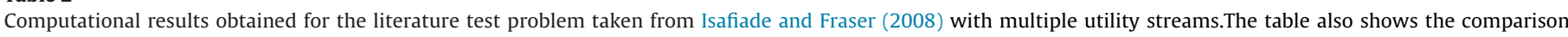

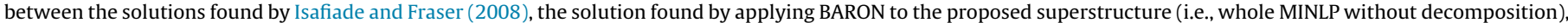
and the solutions found by applying the proposed two-stage MINLP decomposition algorithm.

\begin{tabular}{|c|c|c|c|c|c|}
\hline Results & $\begin{array}{l}\text { (Isafiade and Fraser, } \\
\text { 2008) minimum TAC }\end{array}$ & $\begin{array}{l}\text { (Isafiade and Fraser, } \\
\text { 2008) min num of HXs }\end{array}$ & BARON solution & Starting solution & Best solution of VNS \\
\hline HPS load [kW] & 4298.5 & 5928.5 & 2529.84 & 3009 & 4228.7 \\
\hline MPS load [kW] & 4033.4 & 1852 & 5384.02 & 5432 & 4098 \\
\hline LPS load [kW] & 1 & - & 0 & 0 & 0 \\
\hline AC load [kW] & 484.5 & - & 0 & 548 & 548 \\
\hline CW load [kW] & 7148 & 7078 & 7213 & 7193 & 7078.7 \\
\hline $\mathrm{TAC}, \mathrm{M} \$ / \mathrm{y}$ & 1.1359 & 1.1505 & 1.1365 & 1.1278 & 1.1205 \\
\hline Num. of HXs & 10 & 7 & 10 & 9 & 8 \\
\hline Cost of HXs, M\$/y & - & - & 0.618 & 0.529 & 0.5126 \\
\hline $\begin{array}{l}\text { TAC of worst VNS } \\
\text { solution, M\$/y }\end{array}$ & & & & & 1.1232 \\
\hline $\begin{array}{l}\text { TAC of average VNS } \\
\text { solution, M\$/y }\end{array}$ & & & & & 1.1218 \\
\hline
\end{tabular}

hot streams HPS, MPS and LPS have been considered as UHEN utility streams (those which can be integrated within the HEN) at constant temperature (i.e., condensers). The cold utility streams AC (Air Cooling) and CW (Cooling Water) have been considered respectively as UHEN and UEND utilities.

Six temperature stages have been considered in the HEN superstructure yielding 133 binary variables.

First we tried to solve the whole MINLP (described in Section 3) using BARON version 17.1.2, one of the best commercially available algorithms for non-convex MINLP. We performed several tests with different options (i.e., MILP solvers and NLP solvers) and the best solution found after $25,000 \mathrm{~s}$ has an objective function value equal to $1.136552 \mathrm{M} \$ / \mathrm{y}$. The solution found by BARON is still suboptimal compared to the best solution found by the proposed two-stage algorithm (see Table 2). Besides, the difference with respect to the lower bound returned by BARON, equal to $264,398 \$ / y$, suggests that a significantly longer computational time would be required to reach convergence of the BARON's algorithm.

As far as the proposed two-stage algorithm is concerned, a branch-and-bound gap for the MILP solver of the initialization procedure equal to $1 \%$ and 30000 function evaluations of the VNS algorithm have been set. The computational time on a single-core computer is in the range 1-20 s for the initialization procedure (depending on the values of the minimum difference of temperatures between streams set as parameters) and $3500 \mathrm{~s}$ for the two-stage MINLP algorithm. The optimization has been repeated 10 times in order to account for the stochastic nature of the VNS algorithm. The objective function value (total annual cost of the plant) of the best solution found by VNS is equal to $1.1205 \mathrm{M} \$ / \mathrm{y}$. Thanks to the good starting point found by the initialization procedure (which lies in a neighborhood of the optimal one), the VNS algorithm returns solutions quite close to the best one in all the runs, as indicated by the small difference between the TAC of the best and worst solution reported in Table 2. It is important to note that, if random starting points were used for the VNS algorithm, a larger difference between best and worst solutions would be found (and worse solutions in general) owing to the higher risk of finding local optima. Table 2 shows also the comparison of the best solution found by the two-stage algorithm with the two solutions found by Isafiade and Fraser (2008), the first one looking for the minimum total annual cost one and the second one looking for the minimum number of HXs. Fig. 6 shows the scheme of the best solution found.

It is worth noticing that the best solution found by the VNS is better than the best solution found by Isafiade and Fraser (2008). This is due not only to the effectiveness of the two-stage algorithm but also to the higher flexibility of the temperature stage superstructure considered in this work. As explained in Section 2, the interval-based superstructure of Isafiade and Fraser (2008)) is not as flexible as that of Yee and Grossmann (1990), because the temperature stages are defined on the basis of the supply and target temperatures of the hot streams, thus (1) the matches of each cold stream with the hot streams are necessarily sequenced according to the order of temperatures of the hot streams, (2) some streams with narrow temperature range can have only one stage. In the solution found by Isafiade and Fraser (2008), the hot stream "H1" exists in only one stage and it is matched in parallel with the cold streams "C2" and "C3". Although more advantageous for the total annual cost, their superstructure do not allow to match "H1" with the cooling air (as shown in Fig. 6) because this would require an additional temperature stage. 


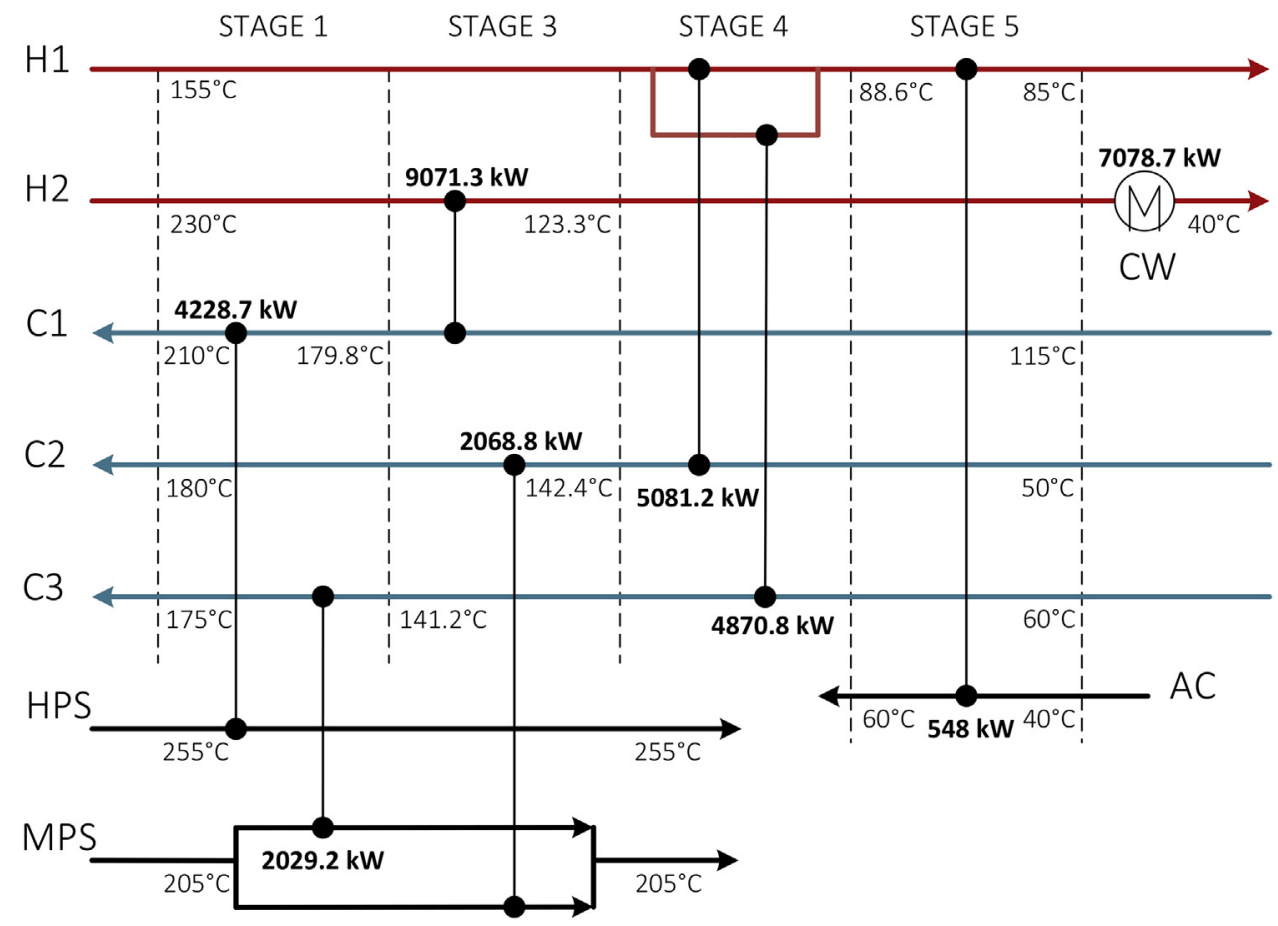

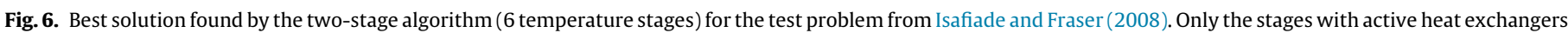
are represented.

Table 3

Process and utility stream data of the HRSG test problem.

\begin{tabular}{|c|c|c|c|}
\hline Process stream & $\mathrm{F}[\mathrm{kW} / \mathrm{K}]$ & $\mathrm{T}_{\mathrm{IN}}\left[{ }^{\circ} \mathrm{C}\right]$ & $\mathrm{T}_{\text {OUT }}\left[{ }^{\circ} \mathrm{C}\right]$ \\
\hline $\mathrm{H} 1$ & 672.90 & 566.4 & $\geq 100$ \\
\hline Utility streams & $\Delta \mathrm{h}[\mathrm{kJ} / \mathrm{kg}]$ & $\mathrm{T}_{\text {IN }}\left[{ }^{\circ} \mathrm{C}\right]$ & $\mathrm{T}_{\text {OUT }}\left[{ }^{\circ} \mathrm{C}\right]$ \\
\hline Cooling Water & 41.8 & 15 & 25 \\
\hline Economizer HP & 1545.6 & 30 & 352 \\
\hline Evaporator HP & 857 & 352 & 352 \\
\hline Superheater HP & 868 & 352 & 545 \\
\hline Reheater HP & 542 & 295.7 & 545 \\
\hline Condenser HP & 2246 & 30 & 30 \\
\hline Economizer MP & 913.7 & 30 & 242.5 \\
\hline Evaporator MP & 1752 & 242.5 & 242.5 \\
\hline Superheater MP & 751 & 242.5 & 545 \\
\hline Condenser MP & 2246 & 30 & 30 \\
\hline Economizer LP & 511.6 & 30 & 151.8 \\
\hline Evaporator LP & 2107 & 151.8 & 151.8 \\
\hline Superheater LP & 241 & 151.8 & 267 \\
\hline Condenser LP & 2246 & 30 & 30 \\
\hline
\end{tabular}

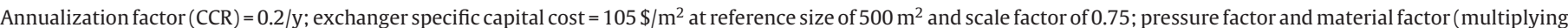

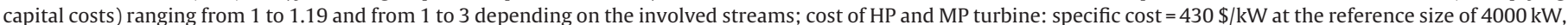

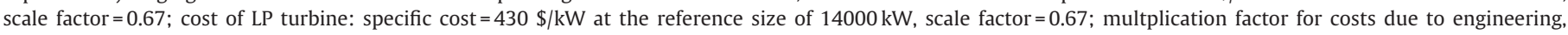
procurement \& construction $=2$; equivalent operating hours $=7000 \mathrm{~h} / \mathrm{y}$; electricity selling price $=0.080 \$ / \mathrm{kWh}$; cooling water cost $=20 \$ / \mathrm{kWyear}$.

\subsection{HRSG of a natural-gas-fired combined cycle}

The method has been tested on the optimization of a triple-pressure-level Heat Recovery Steam Generator (HRSG) of a natural-gas-fired combined cycle. The hot process stream considered in the problem corresponds to the gas turbine flue gases; the utility streams represent the steam and water flows of a triple-pressure-level steam cycle. The data of the flue gases (hot process stream "H1") and of the steam cycle are reported in Table 3. Accurate cost related data for heat exchangers (depending on the material), steam turbine and utility operation and maintenance have been derived from Thermoflow (2015), an ad hoc simulation software, and from real-world projects with the aid of a consultancy company.

As far as the investment costs are considered, simplified but accurate cost models are used to assess the cost of the equipment units (i.e. pumps, heat exchangers and steam turbine). A different bare module cost (also called material cost) is defined for each heat exchanger, 
depending on the type of fluids, their temperatures and their pressures. More in detail, the bare module cost $C_{i j}$ of the heat exchanger between hot stream $i$ and cold stream $j$ is modelled with the following equation Eq. (34):

$$
C_{i j}=F_{M_{i j}} \cdot F_{P_{i j}} \cdot c_{r e f_{i j}} \cdot\left(\frac{A_{i j}}{A_{r e f}}\right)^{f_{i j}}
$$

Where $A_{i j}$ is the area of the heat exchanger between hot stream i and cold stream $\mathrm{j}, F_{M_{i j}}$ is the material factor (ratio between the specific area cost of the material and the specific area cost of carbon steel), depending on the type of material of the heat exchanger (which in turn depend on the nature of the fluids and the temperatures, as specified in the material selection criteria described below), $F_{P_{i j}}$ is the pressure factor, which depends on the maximum pressure among the two involved fluids, $c_{r e f_{i j}}$ is the specific area cost at the reference area $A_{r e f}$, and $f_{i j}$ is the scale-law exponent.

The considered heat exchanger materials and the corresponding material factors considered in this study are reported in the following together with the material selection criteria (which agree with the current industrial practice):

- Carbon steel for all the heat exchangers without corrosive fluids and maximum metal temperature below $350{ }^{\circ} \mathrm{C}(\mathrm{i} . e .$, all economizers and evaporators, material cost factor $F_{M}=1$ )

- P22-T22 (medium grade steel) for heat exchangers without corrosive fluids and maximum metal temperature below $450{ }^{\circ} \mathrm{C}(\mathrm{i} . e .$, for $\mathrm{SH}$ LP, material cost factor $F_{M}=2$ )

- High grade steel T91-T92 between $450^{\circ} \mathrm{C}$ and $600^{\circ} \mathrm{C}$ (i.e., for SH HP, RH and SH MP, material cost factor $F_{M}=3$ ).

The specific area cost and the scale-law exponent were assumed to be $105 \$ / \mathrm{m}^{2}$ (at reference area of $10000 \mathrm{~m}^{2}$ ) and 0.75 respectively. $F_{P_{i j}}$ as a function of the stream pressures has been taken from Ulrich (1984) for HXs with pressure only on the tube side.

The steam turbine cost has been determined section by section (HP, MP, and LP) using as basis the results of calculations made with Thermoflow (2015), a widely used commercial software for the simulation and economic analysis of power plants. Since the inlet and outlet pressure and temperature of the steam are fixed, the bare module cost of each steam turbine section $\left(C_{\text {section }}\right)$ is assumed to depend mainly on the output power $P_{\text {section }}$ of each section with an economy-of-scale effect, as indicated in Eq. (35):

$$
C_{\text {section }}=c_{\text {ref,section }} \cdot\left(\frac{P_{\text {section }}}{P_{\text {ref,section }}}\right)^{f_{\text {section }}}
$$

The considered specific costs and the corresponding reference sizes and scale factors for each section of the turbine considered in this study are as following:

- HP and MP level: specific cost $=430 \$ / \mathrm{kW}$ at the reference size of $4000 \mathrm{~kW}$, scale factor $=0.67$

- LP level: specific cost $=430 \$ / \mathrm{kW}$ at the reference size of $14000 \mathrm{~kW}$, scale factor $=0.67$.

The LP level is more expensive because it is a condensing turbine section.

The total bare module (TBM) cost of the components of the plant is obtained by summing the costs of the heat exchangers (between process-process, process-utility and utility-utility streams) and turbine sections. The total plant cost (TPC, total cost of the HEN + HRSC) is then assessed by multiplying the total bare module cost by a multiplication factor $(M=2)$ which accounts for the installation costs, associated civil works, engineering and procurement, contingencies during construction and owners' costs:

$$
T P C=T B M \cdot M
$$

The total plant cost is finally converted into an annual cost via the Annualization factor (CCR). The Total Annual Cost (TAC) is the sum of the annualized capital costs and the operating costs minus the revenue from selling electricity.

The problem has been solved considering two different cases, with and without stream splitting of the flue gases stream, i.e., the stream "H1" can have matches in parallel or only in series. Forbidden matches have been included so that the cold utility streams (i.e., economizers, evaporators, superheaters and reheater of the three levels) cannot be matched with the HP, MP and LP condensers, as these matches would be impossible in practice. For the case with stream splitting 15 temperature stages have been considered in the HEN superstructure yielding 153 binary variables ( 617 without forbidden matches). For the case without stream splitting 20 temperature stages have been used in the HEN superstructure yielding 203 binary variables ( 817 without forbidden matches). Setting a branch-and-bound gap for the MILP solver of the initialization procedure equal to $15 \%$ for the case with stream splitting, $25 \%$ for the case without stream splitting and 50000 function evaluations of the VNS algorithm, the computational time on a single-core computer is about $150 \mathrm{~s}$ for the MILP solution and $6000 \mathrm{~s}$ for the MINLP in both cases. The optimization has been repeated ten times. The convergence curves (plots of the objective function value of the best solution found as a function of the number of function evaluations) of the first 30000 function evaluations of the VNS algorithm are shown in Fig. 7. After an initial appreciable improvement of the objective function value, the VNS algorithm cannot find improving solutions. The objective function value (total annual cost of the plant) of the best solutions found are respectively equal to - $42.837 \mathrm{M} \$ / \mathrm{y}$ (being a negative value, it is a revenue) for the case with stream splitting and $-41.185 \mathrm{M} \$ / \mathrm{y}$ for the case without stream splitting. Thanks to the good starting point found by the initialization procedure, the VNS algorithm returns solutions quite close to the best one in all runs, as indicated by the small difference between the TAC of the best and worst solutions reported in Table 4. It is important to note that, if a random starting point were used for the VNS algorithm, the returned solutions would be considerably worse (owing to the higher risk of finding local optima), and with a large difference between best and worst solutions found (owing to the stochastic nature of the search algorithm and randomness of the starting points). Table 4 shows also a comparison of the best solutions found by the two-stage algorithm with the reference optimal solution for HRSCs of simple combined cycles proposed by Martelli et al. (2011a). The schemes of the best solutions found for the cases with and without stream splitting are shown in Figs. 8 and 9.

It is worth noting that the solution of the case with splitting and the reference solution by Martelli et al. (2011a) are identical (except for some rounding errors due to the NLP solver). The heat exchanger banks layout found for the case with stream splitting, shown in Fig. 8 , is 


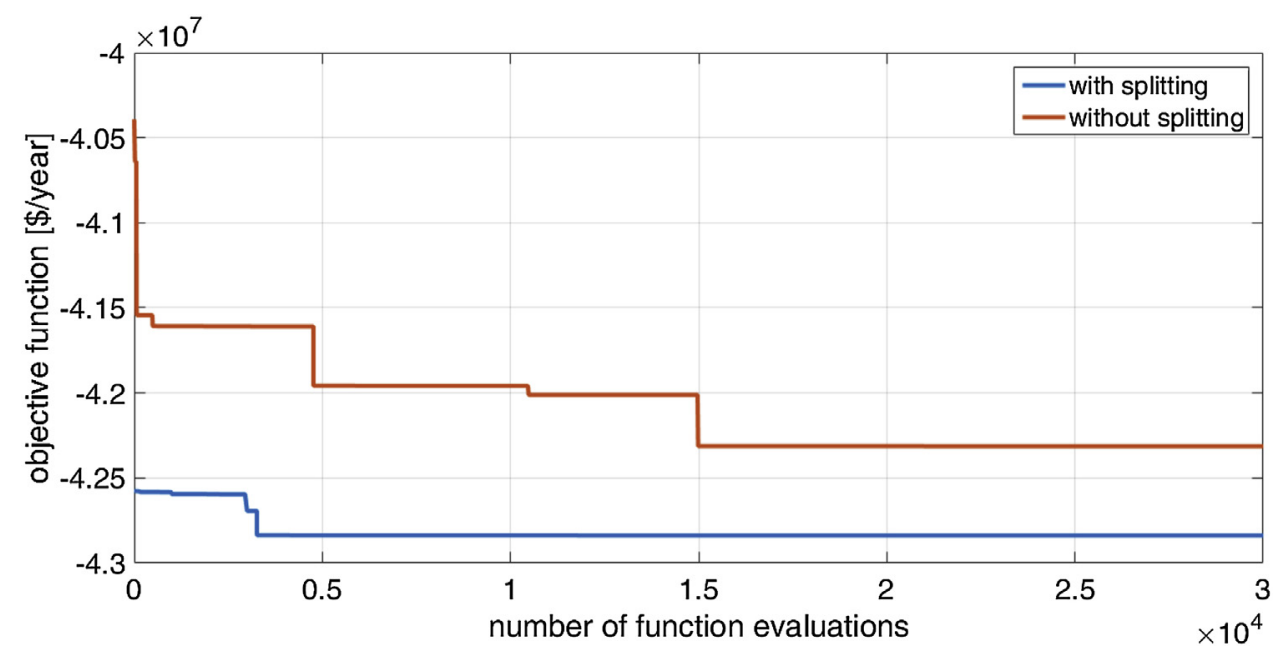

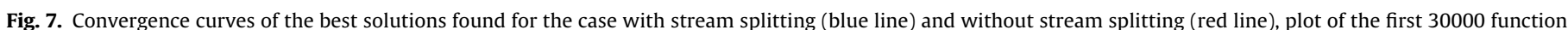

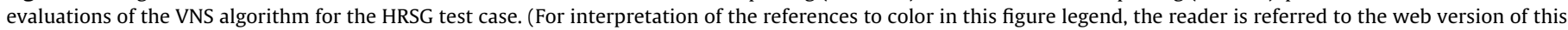
article.)

Table 4

Mass flow rates of the steam cycle in different solutions of the HRSG test problem.

\begin{tabular}{|c|c|c|c|c|c|c|}
\hline Results & $\begin{array}{l}\text { Martelli et al. } \\
(2011 a, b)\end{array}$ & Energy Targeting & $\begin{array}{l}\text { Starting solution with } \\
\text { splitting }\end{array}$ & $\begin{array}{l}\text { Best solution of VNS } \\
\text { with splitting }\end{array}$ & $\begin{array}{l}\text { Starting solution } \\
\text { without splitting }\end{array}$ & $\begin{array}{l}\text { Best solution of } \\
\text { VNS without } \\
\text { splitting }\end{array}$ \\
\hline $\begin{array}{l}\text { HP level flow rate, } \\
\mathrm{kg} / \mathrm{s}\end{array}$ & 53.66 & 58.01 & 54.06 & 53.67 & 56.05 & 61.11 \\
\hline $\begin{array}{l}\text { MP level flow rate, } \\
\mathrm{kg} / \mathrm{s}\end{array}$ & 22.45 & 17.8 & 20.98 & 22.45 & 14.52 & 0 \\
\hline $\begin{array}{l}\text { LP level flow rate, } \\
\mathrm{kg} / \mathrm{s}\end{array}$ & 11.53 & 10.8 & 12.72 & 11.52 & 15.01 & 28.39 \\
\hline $\begin{array}{l}\text { Net HRSC Power, } \\
\text { MW }\end{array}$ & 123.2 & 123.9 & 122.8 & 123.1 & 119.8 & 119.5 \\
\hline $\begin{array}{l}\text { TAC (HRSC + HEN), } \\
\mathrm{M} \$ / \mathrm{y}\end{array}$ & -42.839 & - & -42.576 & -42.838 & -40.392 & -41.185 \\
\hline Num. of HXs & $15(+3 \mathrm{CW})$ & - & $14(+3 \mathrm{CW})$ & $15(+3 \mathrm{CW})$ & $16(+3 C W)$ & $11(+2 C W)$ \\
\hline $\begin{array}{l}\text { Cost of HXs, M\$/y } \\
\text { TAC of worst VNS } \\
\text { solution, M\$/y }\end{array}$ & 10.317 & - & 10.416 & $\begin{array}{l}10.318 \\
-42.578\end{array}$ & 11.157 & $\begin{array}{l}10.034 \\
-41.156\end{array}$ \\
\hline $\begin{array}{l}\text { TAC of average VNS } \\
\text { solution, } \mathrm{M} \$ / \mathrm{y}\end{array}$ & & & & -42.712 & & -41.177 \\
\hline
\end{tabular}

close to the global optimum, featuring the best trade-off between investment costs and operation costs and revenues. However, the steam tube banks of HRSGs are typically arranged in series and not in parallel for technical and economic reasons in industrial applications, as explained in Section 1. This makes necessary to repeat the optimization including the no stream splitting constraint on the hot stream (hot flue gases). As indicated in Table 4, compared to Martelli et al. (2011a), the best solution found by the VNS algorithm with the no stream splitting constraint shows a slightly worse objective function (+4\% total annual costs) and output power ( $-3 \%)$. The optimal HRSG and steam cycle designs are completely different from the case with stream splitting. Indeed it features a double pressure level steam cycle (only the HP level and the LP level of the steam cycle are activated and used). HP steam superheating and reheating are split into two heat exchangers and placed in series in 4 consecutive stages. The HP economizing is split into three exchangers that are placed in series, separated first by the LP superheater in between, then by the series of LP evaporator and the LP economizer. As a proof of the quality of the returned solution, it is important to note that the HRSG layout (sequence and arrangement of the tube banks) coincides with that typically adopted in the power industry for double-pressure level HRSGs. The deactivation of the MP level is likely due to the high cost of the MP $\mathrm{SH}$, which, because of the no stream splitting constraint, should be further split into two smaller sections (e.g., SH MP high temperature and SH MP low temperature) yielding a considerable increase in the investment costs. In practice, to avoid this issue, the SH MP is often merged with the RH (SH MP steam and RH steam are mixed and heated up within the same tube banks). In order to reproduce such an improved HRSG configuration, a steam cycle superstructure allowing also non-isothermal stream mixing is necessary. Such an analysis will be object of a future work.

\subsection{IGCC}

The method has been tested on an industrial test case, the optimization of the HEN and triple-pressure-level heat recovery steam cycle (HRSC) of an Integrated Gasification Combined Cycle (IGCC) plant with $\mathrm{CO}_{2}$ capture based on the Shell gasifier (Martelli et al., 2011b). Process and utility stream data are reported in Table 5. Notice that the steam cycle streams data are the same as for the HRSG test case. Accurate cost related data for heat exchangers (depending on the pressures and material), steam turbine and utility operation and maintenance have been derived from Thermoflex ${ }^{\circledR}$, an ad hoc simulation software, and from real-world projects with the aid of a consultancy company. 


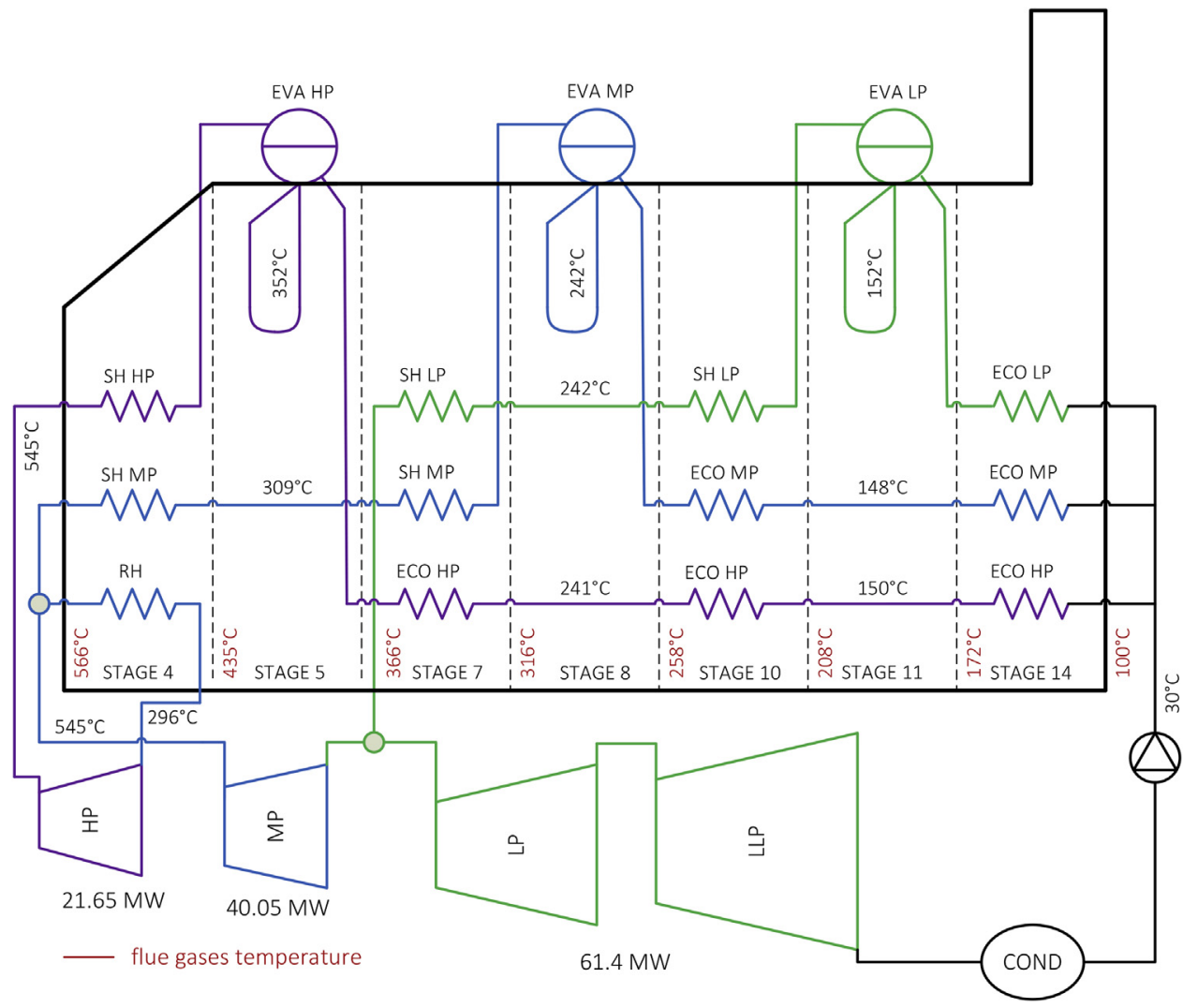

Fig. 8. Best solution found by the two-stage algorithm (15 temperature stages) for the HRSG test case without no stream splitting constraint.

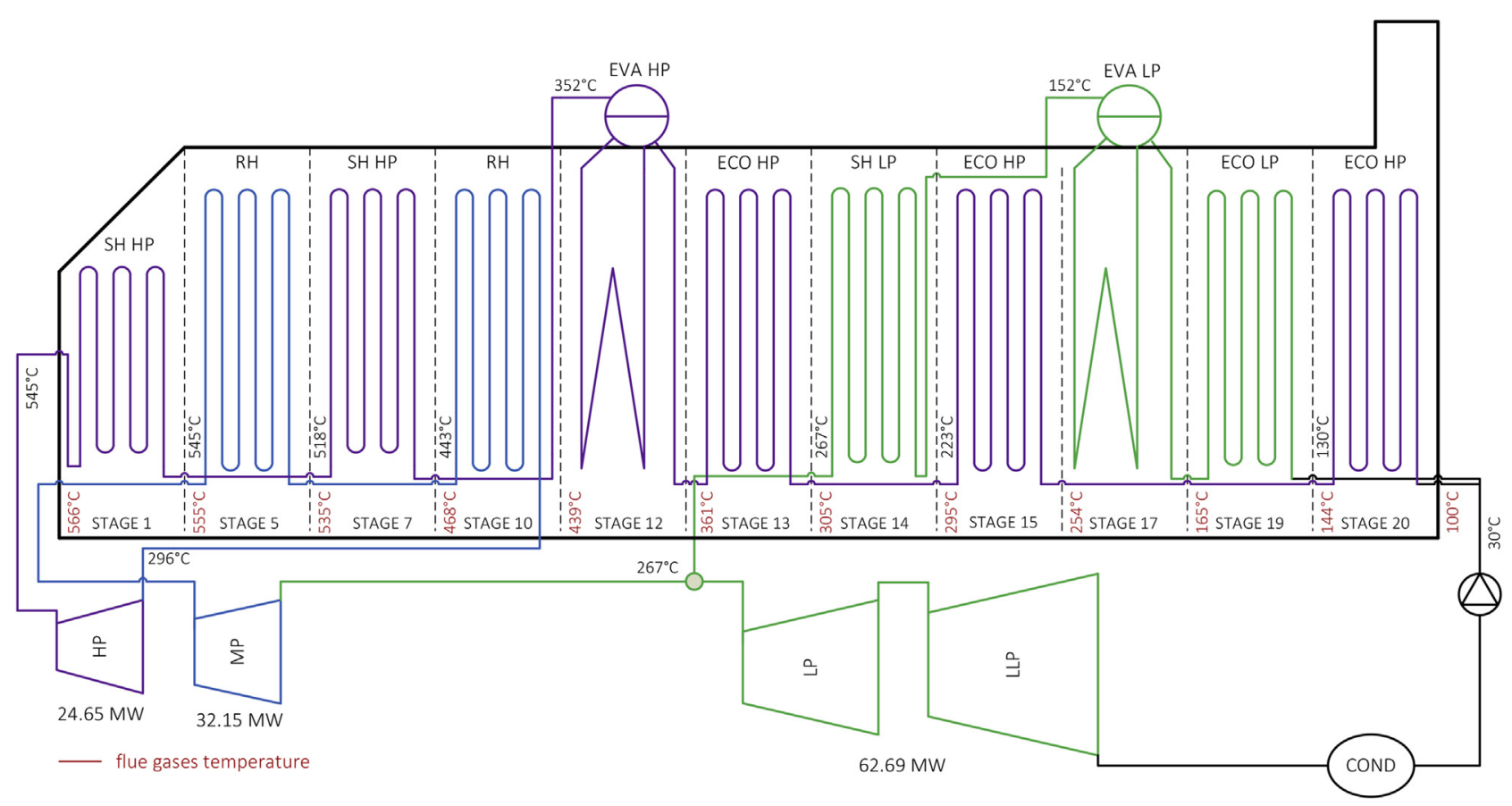

Fig. 9. Best solution found by the two-stage algorithm (20 temperature stages) for the HRSG test case without stream splitting.

The same cost assumptions described for the NGCC test case have been considered for the tubes of the HRSG (i.e., those involving stream H1). For the cost of the syngas coolers, higher HX costs and different pressure factors have been considered. Details are reported in Table 5.

The composite curve and gran composite curve corresponding to the Energy Targeting step are in Fig. 10. The Energy Targeting methodology finds that the optimized HRSC uses all the three available pressure levels of the steam cycle and employs the following mass flow rates: $112.01 \mathrm{~kg} / \mathrm{s}$ for the HP level, $35.3 \mathrm{~kg} / \mathrm{s}$ for the HP level and $16.51 \mathrm{~kg} / \mathrm{s}$ for the HP level. These values have been set as preliminary guesses for the following two-stage MINLP problem. 
Table 5

Process and utility stream data of the IGCC test problem.

\begin{tabular}{|c|c|c|c|}
\hline Hot streams & $\mathrm{F}[\mathrm{kW} / \mathrm{K}]$ & $\mathrm{T}_{\mathrm{IN}}\left[{ }^{\circ} \mathrm{C}\right]$ & $\mathrm{T}_{\text {OUT }}\left[{ }^{\circ} \mathrm{C}\right]$ \\
\hline $\mathrm{H} 1$ & 672.90 & 566.4 & $\geq 100$ \\
\hline $\mathrm{H} 2$ & 185.06 & 900 & 650 \\
\hline H3 & 185.06 & 650 & 250 \\
\hline $\mathrm{H} 4$ & 286.80 & 466 & 250 \\
\hline H5 & 283.82 & 276.8 & 188 \\
\hline $\mathrm{H} 6$ & 1707.87 & 188 & 150 \\
\hline $\mathrm{H} 7$ & 772.32 & 150 & 45 \\
\hline $\mathrm{H} 8$ & 36.47 & 222 & 45 \\
\hline H9 & $13856 \mathrm{~kW}$ & 1200 & 1200 \\
\hline Cold streams & $\mathrm{F}[\mathrm{kW} / \mathrm{K}]$ & $\mathrm{T}_{\mathrm{IN}}\left[{ }^{\circ} \mathrm{C}\right]$ & $\mathrm{T}_{\text {OUT }}\left[{ }^{\circ} \mathrm{C}\right]$ \\
\hline $\mathrm{C} 1$ & 121.98 & 167 & 200 \\
\hline $\mathrm{C} 2$ & 625 & 130 & 170 \\
\hline $\mathrm{C} 3$ & 111.1 & 35 & 170 \\
\hline C4 & 200 & 35 & 60 \\
\hline Utility streams & $\mathrm{T}_{\mathrm{IN}}\left[{ }^{\circ} \mathrm{C}\right]$ & $\mathrm{T}_{\text {OUT }}\left[{ }^{\circ} \mathrm{C}\right]$ & \\
\hline Cooling Water & 15 & 25 & \\
\hline Economizer HP & 30 & 352 & \\
\hline Evaporator HP & 352 & 352 & \\
\hline Superheater HP & 352 & 545 & \\
\hline Reheater HP & 295.7 & 545 & \\
\hline Condenser HP & 30 & 30 & \\
\hline Economizer MP & 30 & 242.5 & \\
\hline Evaporator MP & 242.5 & 242.5 & \\
\hline Superheater MP & 242.5 & 545 & \\
\hline Condenser MP & 30 & 30 & \\
\hline Economizer LP & 30 & 151.8 & \\
\hline Evaporator LP & 151.8 & 151.8 & \\
\hline Superheater LP & 151.8 & 267 & \\
\hline Condenser LP & 30 & 30 & \\
\hline
\end{tabular}

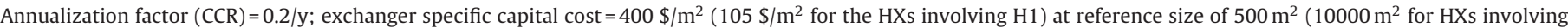

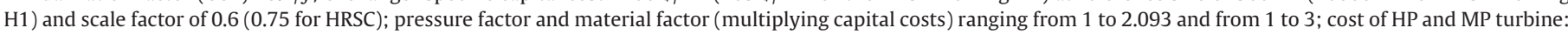

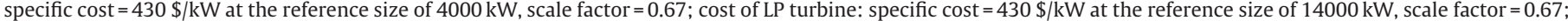

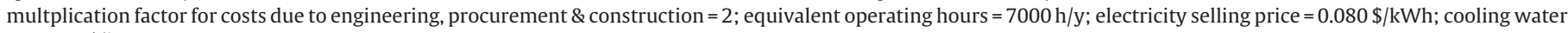
cost $=20 \$ / \mathrm{kWyear}$.

(a)

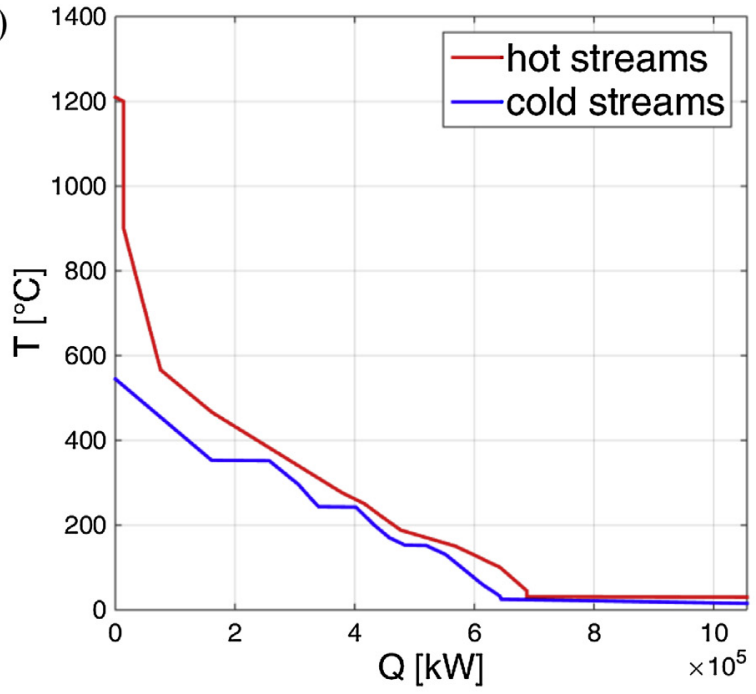

(b)

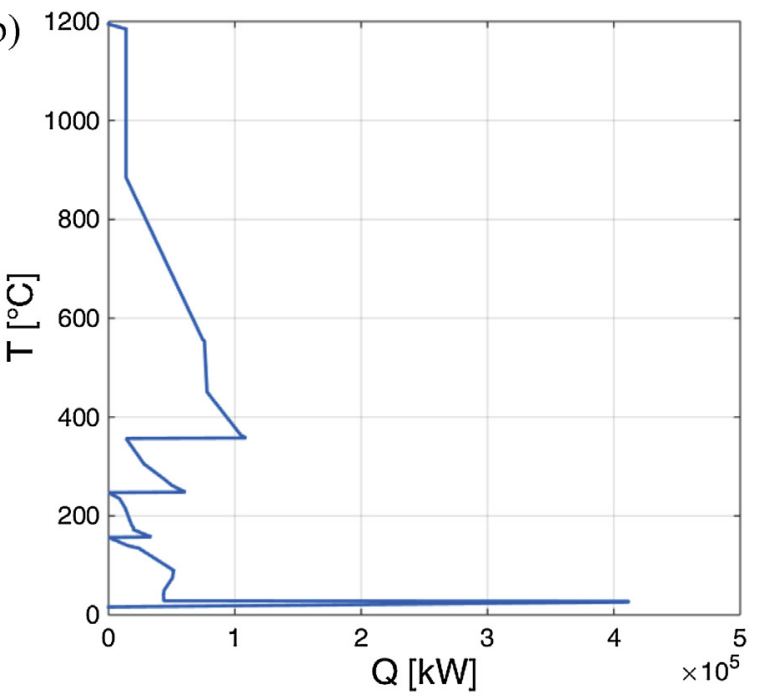

Fig. 10. Composite Curve (a) and Grand Composite Curve (b) generated with the Energy Targeting methodology for the IGCC test case.

The problem has been solved considering two different cases, with and without the "no stream splitting" constraint. In the case without stream splitting, the "no stream splitting" constraint has been applied to all the hot process streams of the problem (i.e., to forbid that the tube banks of steam are placed in parallel within the HRSG or the syngas coolers). Fifteen temperature stages have been considered in the HEN superstructure yielding 1664 binary variables. Forbidden matches, corresponding to technical limitations, have been included: the process stream "H2", corresponding to a high temperature syngas cooler, can be matched only with the HP evaporator or the MP evaporator (Martelli et al., 2011a); in the same way the stream "H9", representing a gasifier, can be coupled only with the MP evaporator (Martelli et al., 2011a,b). Due to the large number of integer variables, it was necessary to set a large branch-and-bound gap for the MILP solver of the initialization procedure. We set a gap of $30 \%$ for the case with allowed stream splitting, $40 \%$ for the case without stream 


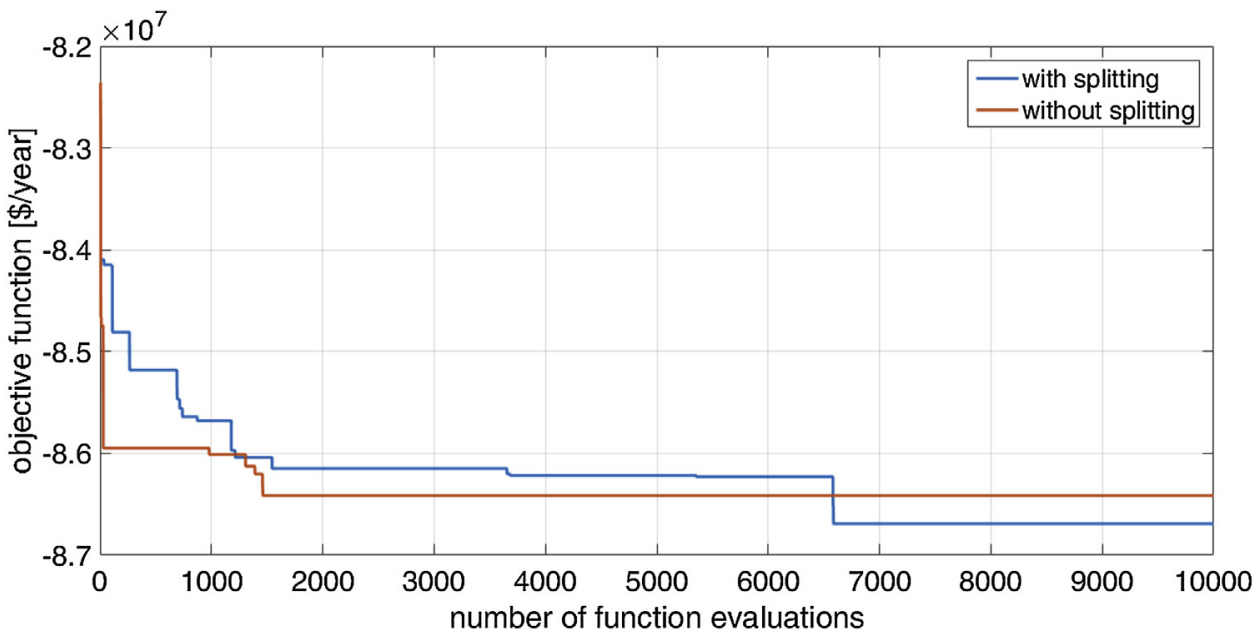

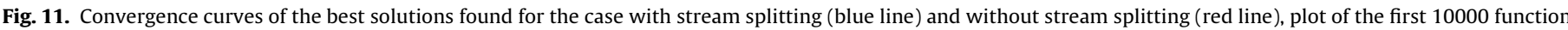

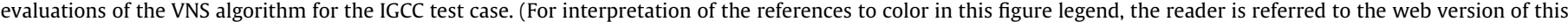
article.)

Table 6

Mass flow rates of the steam cycle in different solutions of the IGCC test problem.

\begin{tabular}{|c|c|c|c|c|c|c|}
\hline Results & Martelli et al. (2011a) & Energy Targeting & $\begin{array}{l}\text { Starting solution with } \\
\text { splitting }\end{array}$ & $\begin{array}{l}\text { Best solution of VNS } \\
\text { with splitting }\end{array}$ & $\begin{array}{l}\text { Starting solution } \\
\text { without splitting }\end{array}$ & $\begin{array}{l}\text { Best solution of VNS } \\
\text { without splitting }\end{array}$ \\
\hline HP level flow rate, $\mathrm{kg} / \mathrm{s}$ & 113.57 & 112.01 & 103.6 & 97.66 & 112.01 & 100.44 \\
\hline MP level flow rate, $\mathrm{kg} / \mathrm{s}$ & 35.66 & 35.3 & 39.29 & 43.91 & 7.91 & 46.54 \\
\hline LP level flow rate, $\mathrm{kg} / \mathrm{s}$ & 18.85 & 16.51 & 24.93 & 34.88 & 48.0 & 24.02 \\
\hline Net HRSC Power, MW & 242.1 & 237.45 & 234.54 & 237.49 & 225.92 & 237.64 \\
\hline $\begin{array}{l}\text { TAC (HRSC + HEN), } \\
\mathrm{M} \$ / \mathrm{y}\end{array}$ & -77.635 & - & -84.097 & -86.692 & -82.358 & -86.415 \\
\hline Num. of HXs & $54(+8 C W)$ & - & $27(+4 C W)$ & $27(+4 C W)$ & $24(+4 \mathrm{CW})$ & $28(+4 C W)$ \\
\hline Cost of HXs, M\$/y & 30.724 & - & 20.355 & 19.603 & 18.224 & 20.151 \\
\hline $\begin{array}{l}\text { TAC of worst VNS } \\
\text { solution, M\$/y }\end{array}$ & & & & -85.256 & & -84.736 \\
\hline $\begin{array}{l}\text { TAC of average VNS } \\
\text { solution, M\$/y }\end{array}$ & & & & -85.945 & & -85.582 \\
\hline
\end{tabular}

splitting. As for the two-stage MINLP algorithm we set a limit of 50000 function evaluations of the VNS algorithm. The computational time on a single-core computer is respectively about $800 \mathrm{~s}$ for the MILP solution with stream splitting, about $1500 \mathrm{~s}$ for the MILP solution with "no stream splitting" and $6000 \mathrm{~s}$ for the two-stage MINLP algorithm (in both cases). The optimization has been repeated ten times. The convergence curves (plots of the objective function value of the best found solution as a function of the number of function evaluations) of the best run of the VNS algorithm are shown in Fig. 11. The objective function value (total annual cost of the plant) of the best solutions found are respectively equal to $-86.692 \mathrm{M} \$ / \mathrm{y}$ (being a negative value, it is a revenue) for the case with stream splitting and -86.415 $\mathrm{M} \$ / \mathrm{y}$ for the case without stream splitting. Compared to the simpler test cases shown in the previous sections, the difference between the TAC of the best and worst solutions found by VNS (see Table 6) is more appreciable. The main reasons are (i) the lower quality of the starting solution (found by the initialization procedure) which is apparently more distant from the optimum compared to the previous test cases, (ii) the larger number of integer variables which greatly increase the number of integer combinations to be explored by the VNS algorithm. Reasons (i) and (ii) increase the risk of finding local minima. Nevertheless, in all the runs, the VNS algorithm appreciably improves the starting point. Indeed, the returned solutions are on average less than $1 \%$ suboptimal (in terms of TAC) compared to the best found solutions.

Table 6 shows also a comparison of the best solutions with that obtained with the method proposed by Martelli et al. (2011a) for the optimization of integrated HRSCs. The best solution found for the cases with and without stream splitting are shown in Figs. 12 and 13 . It is worth noting that in both cases with and without stream splitting the initialization procedure, although sequential, finds a solution with a good balance between utility and heat exchanger costs. Then, the two-stage MINLP algorithm further improves the solution by finding a HEN configuration with better trade-off between costs and efficiency. In both cases, all the three pressure levels of the HRSC are active. In the case with stream splitting, HP steam superheating and MP steam superheating are split into two heat exchangers, while steam reheating is not split and not placed in the HRSG. The HP superheater is first placed in series with the reheater in the high temperature syngas coolers and then in parallel with the first MP steam superheater in the HRSG. In the case with no stream splitting, MP steam superheating is split into three heat exchangers, while HP steam superheating and steam reheating are not split. The MP superheater is first connected in series with the reheater in the high temperature syngas coolers, then in series before the HP steam superheater in the HRSG and then after the Water Gas Shift process, in series with the MP evaporator. As indicated in Table 6, compared to Martelli et al. (2011a), the two solutions of the VNS algorithm are different in terms of the steam cycle mass flow rates (i.e., lower HP flow, higher MP and LP flows), with lower HRSC output power, but the objective function is significantly improved (more than $11 \%$ in both cases) due to the optimized HEN configuration requiring fewer heat exchangers and heat transfer area. The layout of the HEN is very interesting as it combines energy efficiency, limited number of units, and arrangement linearity. It is worth to note that the solution with the no stream 


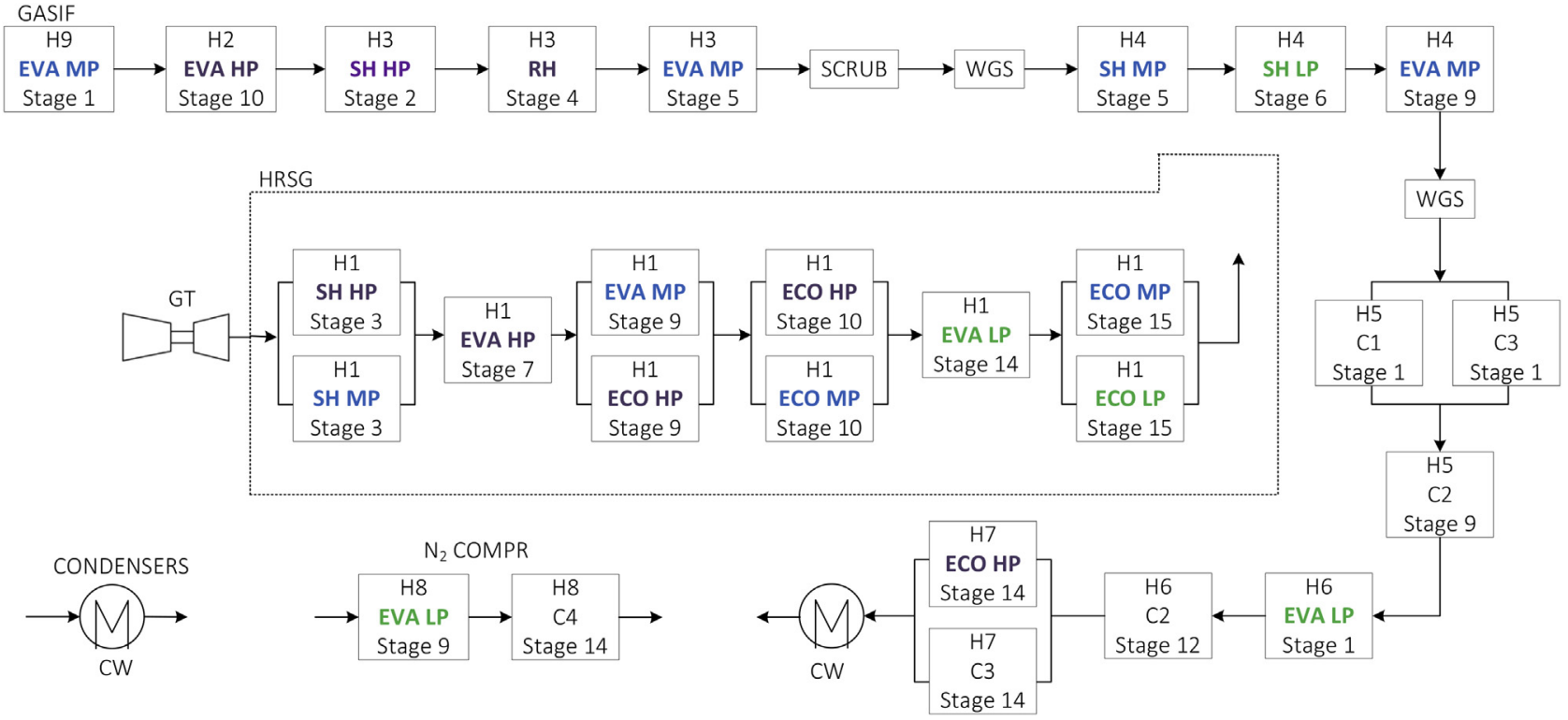

Fig. 12. Best solution found by the two-stage algorithm (15 temperature stages) for the IGCC test case with stream splitting.

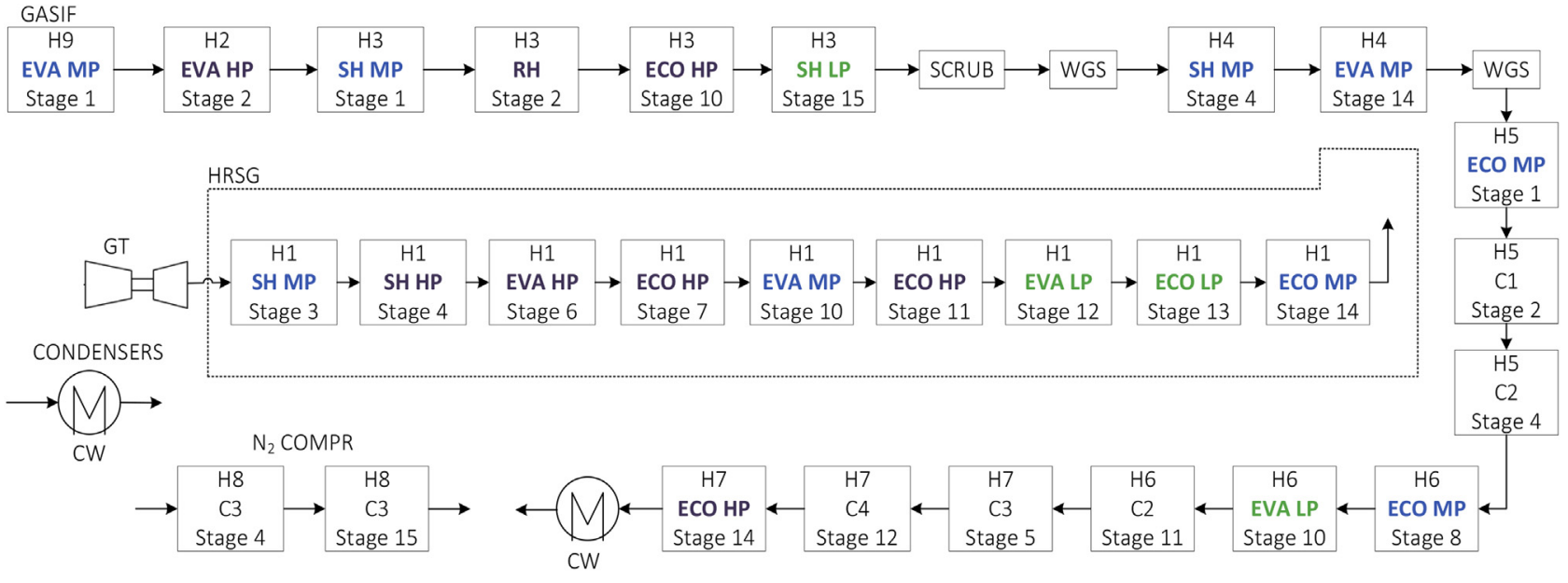

Fig. 13. Best solution found by the two-stage algorithm ( 15 temperature stages) for the IGCC test case without stream splitting.

splitting constraint is essentially not penalized by the "no stream splitting" constraint on the hot streams (very similar total annual costs). This is due to (1) the availability of multiple hot streams (syngas coolers and HRSG) and (2) the high temperature of the hot syngas coolers (compared to the steam temperature) which allow to distribute the cold streams with more freedom compared to the HRSG case (featuring a single hot stream with an inlet temperature close to that of the superheated steam flows).

\section{Conclusions}

A novel approach for the simultaneous synthesis of Heat Exchanger Networks and complex Utility Systems of chemical processes and energy systems has been proposed. The mathematical formulation uses the SYNHEAT superstructure to reproduce the possible HEN arrangements, and ad hoc superstructures and nonlinear models to represent the utility systems. Compared to classic HEN synthesis methods, the proposed methodology returns improved HENs and simple or complex utility system designs (e.g., boiler, multiple-level steam cycle, refrigeration cycle, etc.), in which utility streams are fully integrated within the HEN, exploiting any possible synergy between process and utility, and aiming to identify the best trade-off between utility and HEN costs. The model is able to handle also specific design constraints, such as forbidden/forced matches between hot/cold streams and the no stream splitting constraint, which cannot be handled in the available sequential techniques.

Given the challenging nonconvex MINLP problem associated to the superstructure (which features a nonconvex objective function and bilinear terms in some of the constraints), general-purpose MINLP solvers are not very effective due to the slow convergence rate (as shown in Section 6.1). For this reason, a two-stage algorithm and an ad hoc initialization procedure have been devised. The algorithm uses at the upper level the Variable Neighbourhood Search (VNS) algorithm to optimize the integer variables, and at the lower level the SQP algorithm to optimize the real variables. Good feasible starting points are generated by a specifically developed sequential synthesis procedure. This alleviates the penalty of the slow convergence rate of VNS for large scale problems. Despite the large number of integer variables of the 
test cases (up to 1664), the VNS improved appreciably the generated starting solutions (up to $5 \%$ improvement in the value of the objective function).

The literature test case with multiple utilities shows that the proposed methodology (superstructure and algorithm) is able to find improved solutions compared to previous approaches. This is due not only to the effectiveness of the two-stage algorithm but also to the higher flexibility of the temperature stage superstructure considered in this work. The results obtained with the two real-world test problems also indicate that proposed methodology is very promising. As a proof of the quality of the returned solutions, the solution found for the NGCC without the "no stream splitting" constraint is equal to the best known solution reported in the literature, while the solution found for the case with "no stream splitting" constraint coincides with the typical layout of double-pressure level HRSGs with reheat. In the IGCC test problem, the solution found with the proposed synthesis technique is considerably better than the reference solution (available in the literature and found with a different methodology): even though the total power output is lower, the objective function is significantly improved ( $11 \%$ lower total annual cost) due to the optimized HEN configuration requiring fewer heat exchangers and heat transfer area. The layout of the overall system (HEN ad HRSC) is also very interesting as it combines energy efficiency, limited number of units, and arrangement linearity.

Future works on the methodology will focus on the improvement of the two-stage optimization algorithm (e.g., devising a different decomposition approach or using different evolutionary algorithms for the upper level problem) and on the extension of steam cycle model to handle to non-isothermal mixing and the optimization of stream pressures and temperatures.

\section{Acknowledgments}

The authors acknowledge the Swiss National Science Foundation (SNSF), for having supported this work by funding the visiting period of Prof. Martelli at EPFL (grant number IZKOZ2_157270), and the Swiss Competence Center on Energy Research, Efficiency in Industrial Processes (SCCER-EIP) from the Swiss Confederation Commission for Technology and Innovation. The authors acknowledge also LEAP, Laboratorio Energia Ambiente Piacenza, for having co-funded the research activity of Cristina Elsido.

\section{References}

Bergamini, M.L., Scenna, N.J., Aguirre, P.A., 2007. Global optimal structures of heat exchanger networks by piecewise relaxation. Ind. Eng. Chem. Res. 46, $1752-1763$.

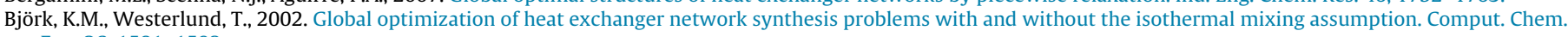
Eng. 26, 1581-1593.

Bruno, J., Fernandez, F., Castells, F., Grossmann, I., 1998. A rigorous MINLP model for the optimal synthesis and operation of utility plants. Trans IChemE 76 (A), 246-258, Retrieved from http://www.sciencedirect.com/science/article/pii/S0263876298716430.

Byrd, R.H., Nocedal, J., Waltz, R.A., 2006. In: Di Pillo, G., Roma, M. (Eds.), KNITRO: An Integrated Package for Nonlinear Optimization. Springer-Verlag.

Chen, J. 1987. Letter to the editors: comments on improvement on a replacement for the logarithmic mean. Chem. Eng. Sci. 42, 2488-2489.

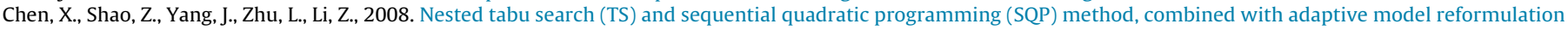
for heat exchanger network synthesis (HENS). Ind. Eng. Chem. Res. 47 (7), 2320-2330.

Ciric, A.R., Floudas, C.A., 1991. Heat exchanger network synthesis without decomposition. Comput. Chem. Eng. 15 (6), 385-396, http://dx.doi.org/10.1016/00981354(91)87017-4.

Dréo, J., Pétrowski, A., Siarry, P., Taillard, E., 2006. Metaheuristics for Hard Optimization. Springer-Verlag, Berlin/Heidelberg, http://dx.doi.org/10.1007/3-540-30966-7.

Drud, S., 1992. CONOPT-a large-scale GRG code. ORSA J. Comput. 6, 207-216.

Duran, M.A., Grossmann, I.E., 1986. Simultaneous optimization and heat integration of chemical processes. AIChE J. 32 (1), 123-138, http://dx.doi.org/10.1002/aic. 690320114.

Egea, J.A., Henriques, D., Cokelaer, T., Villaverde, A.F., MacNamara, A., Danciu, D., et al., 2014. MEIGO: an open-source software suite based on metaheuristics for global optimization in systems biology and bioinformatics. BMC Bioinf. 15, 136, http://dx.doi.org/10.1186/1471-2105-15-136.

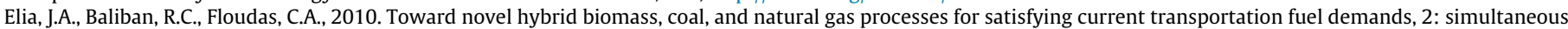
heat and power integration. Ind. Eng. Chem. Res. 49 (16), 7371-7388, http://dx.doi.org/10.1021/ie100064q.

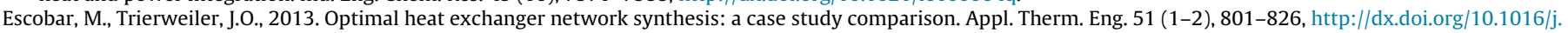
applthermaleng.2012.10.022.

Floudas, C.A., Ciric, A., Grossmann, I., 1986. Automatic synthesis of optimum heat exchanger network configurations. AIChE J. 32 (2), $276-290$.

Furman, K.C., Sahinidis, N.V., 2002. A critical review and annotated bibliography for heat exchanger network synthesis in the 20 th century. Ind. Eng. Chem. Res. 41 (10), 2335-2370, http://dx.doi.org/10.1021/ie010389e.

Gamrath, G., Fischer, T., Gally, T., Ambros, M., Gleixner, G.H., Koch, T., Maher, S.J., et al., 2016. The SCIP Optimization Suite 3.2. ZIB-Report, Berlin. Retrieved from urn:nbn:de:0297-zib-57675.

Gassner, M., Maréchal, F., 2007. Methodology for the optimal thermo-economic, multi-objective design of thermochemical fuel production from biomass. Comput. Chem. Eng., 1-6.

Gill, P.E., Murray, W., Saunders, M.A., 2005. SNOPT: an SQP algorithm for large-scale constrained optimization. SIAM Rev. 47 (1), 99-131.

Isafiade, A., Bogataj, M., Fraser, D., Kravanja, Z., 2015. Optimal synthesis of heat exchanger networks for multi-period operations involving single and multiple utilities. Chem. Eng. Sci. 127, 175-188, http://dx.doi.org/10.1016/j.ces.2014.12.037.

Isafiade, A.J., Fraser, D.M., 2008. Interval-based MINLP superstructure synthesis of heat exchange networks. Chem. Eng. Res. Des. 86, 245-257, http://dx.doi.org/10.1016/j. cherd.2007.11.001.

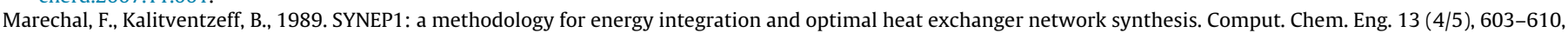
http://dx.doi.org/10.1017/CBO9781107415324.004.

Marechal, F., Kalitventzeff, B., 1998. Process integration: selection optimal utility system. Comput. Chem. Eng. 22, S149-S156.

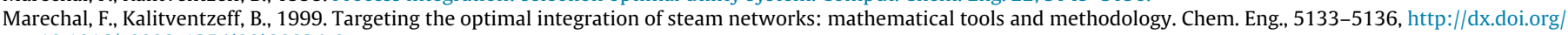
10.1016/s0098-1354(99)80034-9.

Martelli, E., Amaldi, E., 2014. PGS-COM: a hybrid method for constrained non-smooth black-box optimization problems Brief review, novel algorithm and comparative evaluation. Comput. Chem. Eng. 63 (17), 108-139, Retrieved from http://www.sciencedirect.com/science/article/pii/S0098135413003955.

Martelli, E., Amaldi, E., Consonni, S., 2011a. Numerical optimization of heat recovery steam cycles: mathematical model, two-stage algorithm and applications. Comput. Chem. Eng. 35 (12), 2799-2823, Retrieved from http://www.sciencedirect.com/science/article/pii/S0098135411001591.

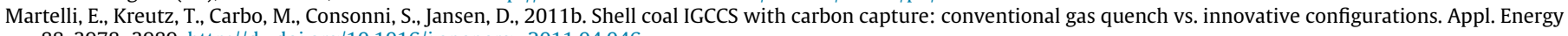
88, 3978-3989, http://dx.doi.org/10.1016/j.apenergy.2011.04.046.

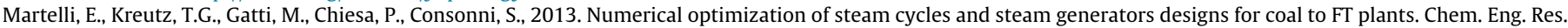
Des. 91 (8), 1467-1482, http://dx.doi.org/10.1016/j.cherd.2013.02.026.

Martelli, E., Nord, L.O., Bolland, O., 2012. Design criteria and optimization of heat recovery steam cycles for integrated reforming combined cycles with $\mathrm{CO}_{2}$ capture. Appl. Energy 92, 255-268, http://dx.doi.org/10.1016/j.apenergy.2011.10.043.

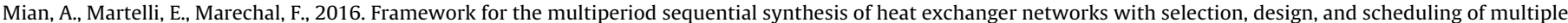
utilities. Ind. Eng. Chem. Res. 55, 168-186, http://dx.doi.org/10.1021/acs.iecr.5b02104.

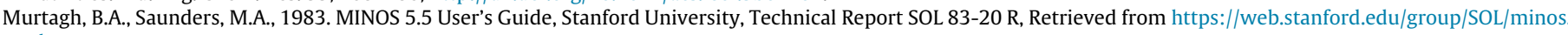
htm. 
Na, J., Jung, J., Park, C., Han, C., 2014. Simultaneous optimization models for heat exchanger network synthesis with multiple utilities: a new strategy by using utility sub-stage. Comput. Aided Chem. Eng. 33, 1675-1680.

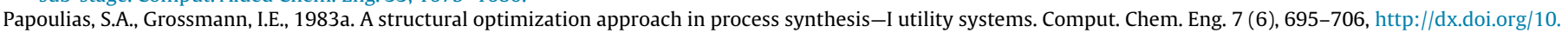
1016/0098-1354(83)85022-4.

Papoulias, S.A., Grossmann, I.E., 1983b. A structural optimization approach in process synthesis-II heat recovery networks. Comput. Chem. Eng. 7 (6), 707-721, http://dx. doi.org/10.1016/0098-1354(83)85023-6.

Papoulias, S.A., Grossmann, I.E., 1983c. A structural optimization approach in process synthesis-III total processing systems. Comput. Chem. Eng. 7 (6), $723-734$.

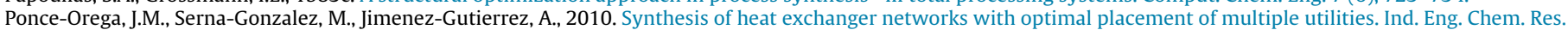
49, 2849-2856.

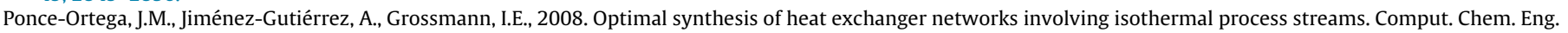
32, 1918-1942, http://dx.doi.org/10.1016/j.compchemeng.2007.10.007.

Tawarmalani, M., Sahinidis, N.V., 2005. A polyhedral branch-and-cut approach to global optimization. Math. Program. 103 (2), $225-249$.

Thermoflow, 2015. Thermoflex v. 24, http://www.thermoflow.com/combinedcycle_TFX.html (Accessed 19 June 2016).

Ulrich, D.G., 1984. A guide to chemical engineering process design and economics. (J. Wiley, Ed.).

Watcher, A., Biegler, L.T., 2005. On the implementation of an interior-point filter line-search algorithm for large-scale nonlinear programming. Math. Program. 106 (1), 25-57.

Yang, L., Grossmann, I.E., 2013. Water targeting models for simultaneous flowsheet optimization. Ind. Eng. Chem. Res. 52.

Yee, T., Grossmann, I., 1990. Simultaneous optimization models for heat integration-II. Heat exchanger network synthesis. Comput. Chem. Eng. 14 (10), 1165-1184, Retrieved from http://www.sciencedirect.com/science/article/pii/0098135490850108. 